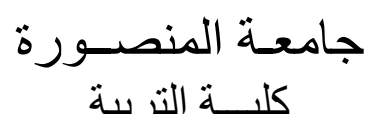

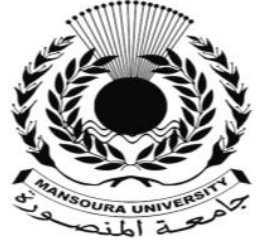

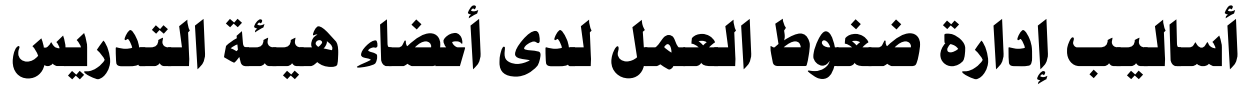 ومهماونيبهم بكليات التربية جاوهمة الهمنصورة دواسهة همبسانة
}

\author{
إعداد \\ الباحثة/ أميرة محمد علي علي إعدي \\ المعيدة بقسم أصول التربية \\ كلية التربية- جامعة المنصورة التربة
}

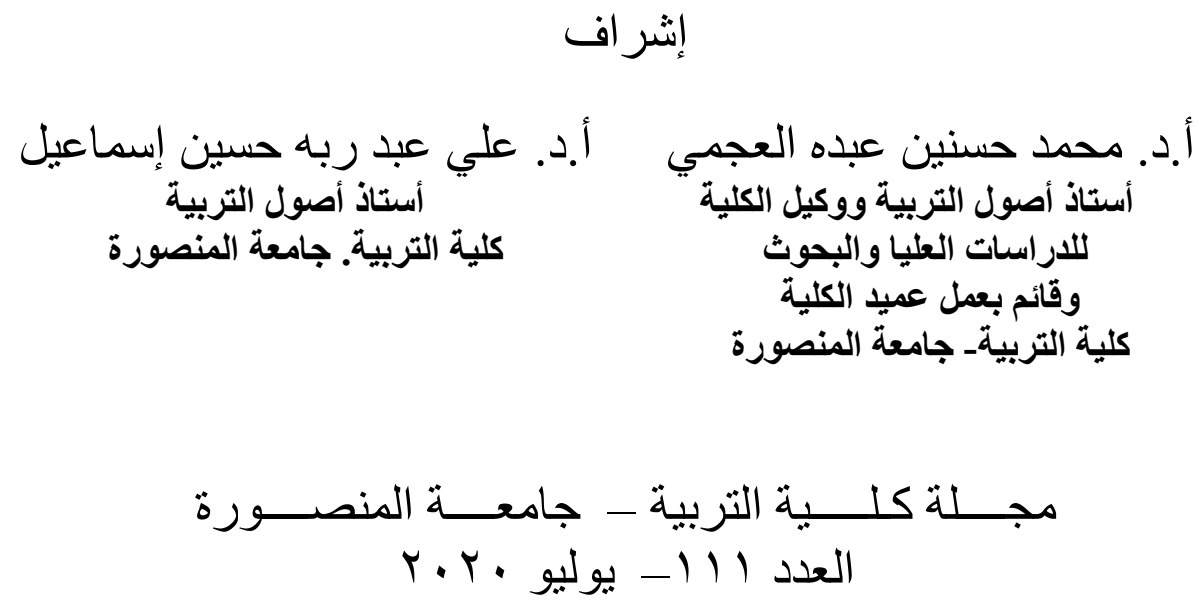


أساليب إدارة ضغوط العمل لدى أعضاء هيئة التدريس ومعاو نيهم بكليات التربية جامعة المنصورة در اسة ميداء هينة التية

أمبرة محمد علي علي

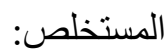

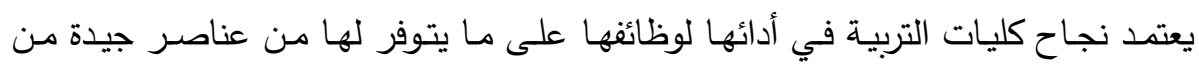

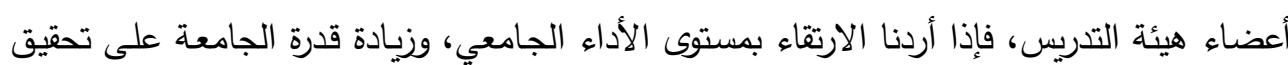

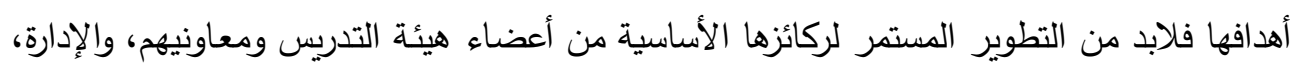
والطلاب، ويعد عضو هيئة التدريس من أهم هذه الركائز.

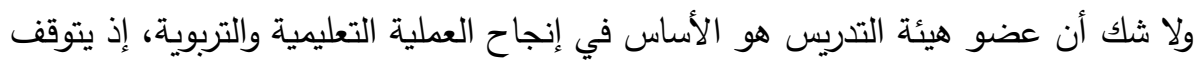

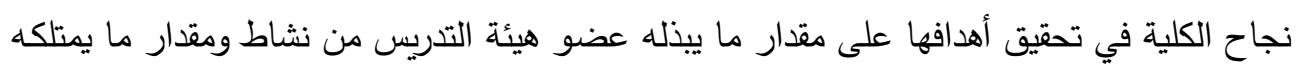

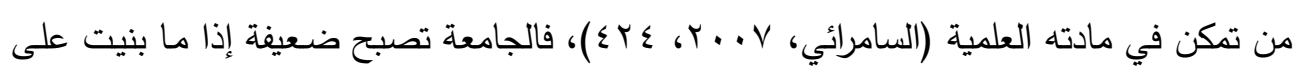

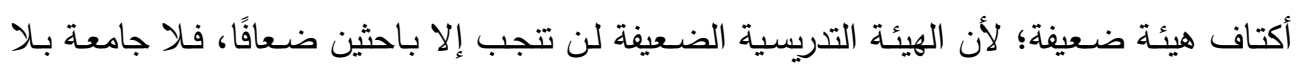

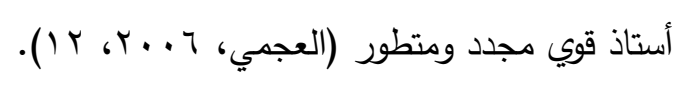

ولذلك يتعرض أعضاء هيئة التدريس ومعاونيهم إلى العديد من الضغوط التي تواجههم داخل

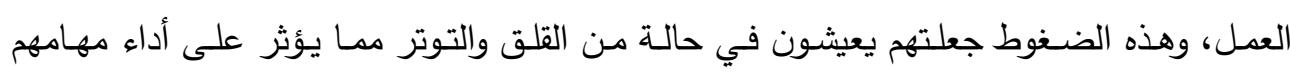

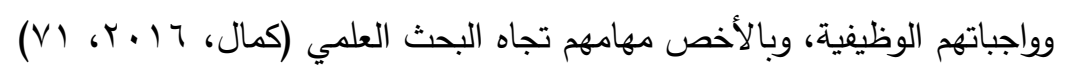

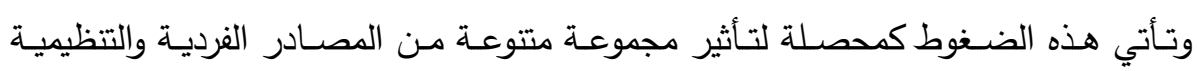

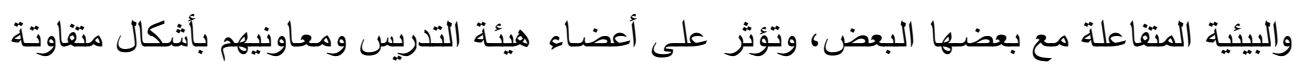

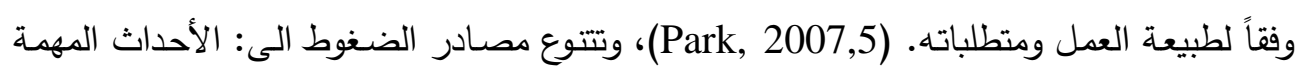

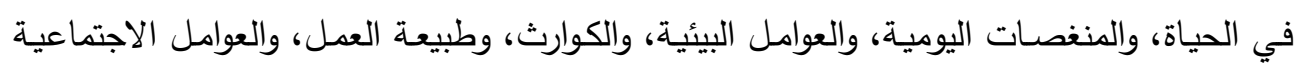

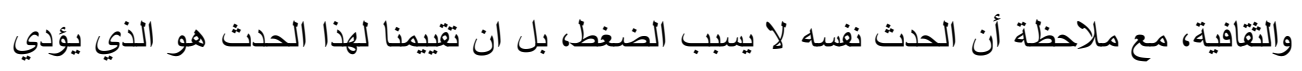

بنا الى أن نشعر بالضغط (Straub,2012, 115)

وتتنوع أساليب إدارة ضغوط العمل التي يستخدمها أعضاء هيئة التدريس ومعاونيهم منها:

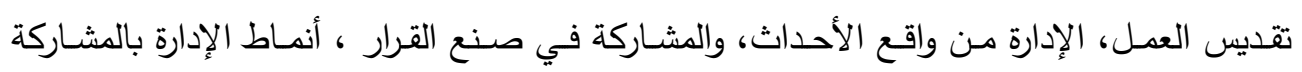

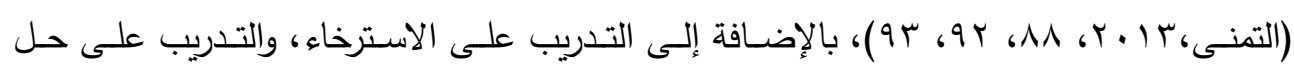

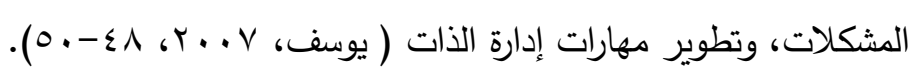




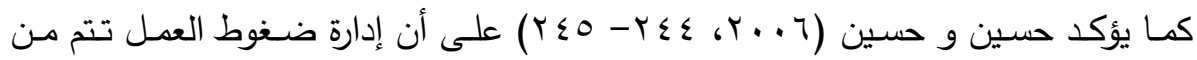
خلال عدة طرق وأساليب مختلفة تهدف إلى تقليل تأثيرها السلبي على أداء أعضاء هيئة التدريس

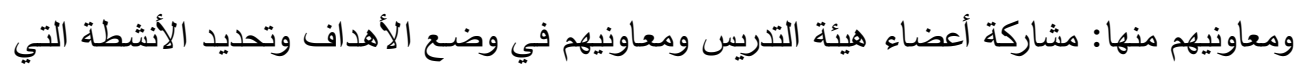

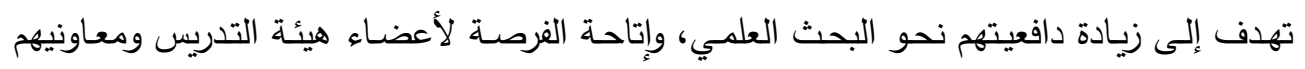
لتعديل أدوارهم في العمل بحيث يتناسب مع ميولهم المهنية، والمساندة الاجتماعية في بيئة العمل. مما سبق جاءت فكرة البحث الحالي حول أساليب إدارة ضغوط عمل أعضاء هيئة التدريس ومعاونيهم بكليات التربية جامعة المنصورة. مشكلة البحث:

يعاني أعضاء هيئة التدريس ومعاونيهج بكليات التربية جامعة المنصورة من ضغوط العمل

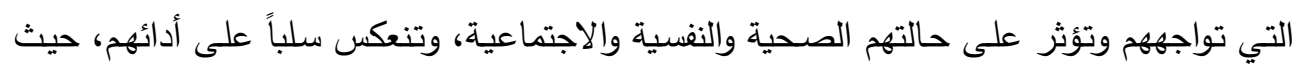

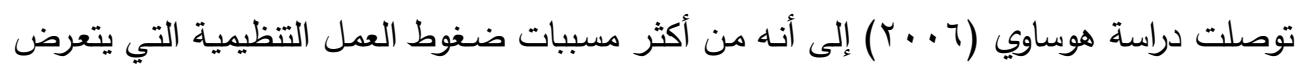

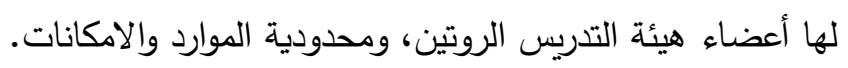

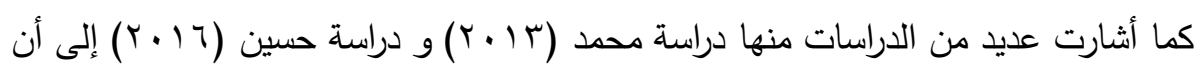

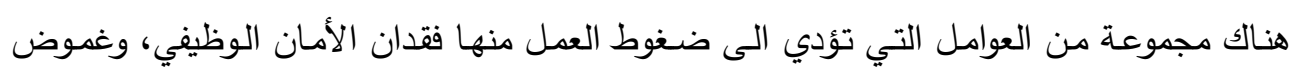

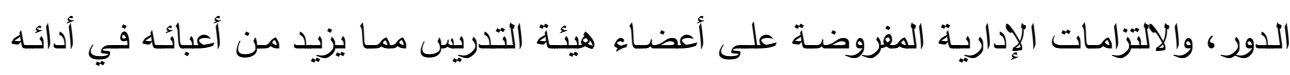
لعمله ويعيق نشاطه البحثي.

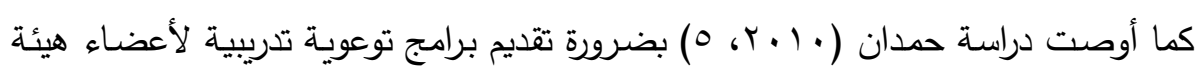
التدريس ومعاونيهم لتقديم الأساليب الفعالة لمواجهة ضغوط العمل والحد من آثارها السلبية، والتقليل

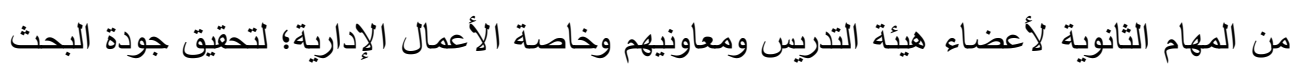

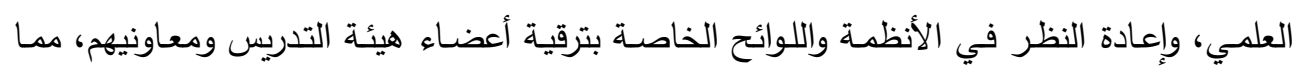
يسهم في خفض ضغوط واعل العمل لديهم. مما سبق تتحدد مشكلة البحث الحالي في التساؤلات التالية:

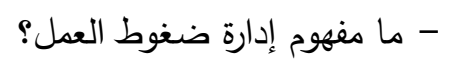
- مـا مراحل إدارة ضـغوط العهل لدى أعضـاء هيئة التدريس ومعـاونيهم بكليات التربيـة جامعـة

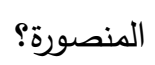

- مـا أهم الأسـاليب التي يمكن أن يستخدمها أعضـاء هيئة التدريس ومعـاونيهم بكليات التربيـة

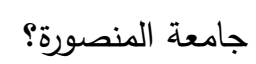


- ما أهم التوصيات والمقترحات لتحديد الأساليب المناسبة لإدارة ضغوط العمل لدى أعضاء هيئة التدريس ومعاونيهم بكليات التربية جامعة المنصورة؟ التمبن هدف البحث:

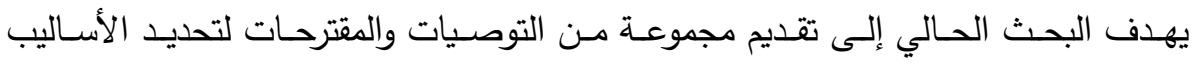
المناسبة لإدارة ضغوط العمل لدى أعضاء هيئة التدريس ومعاونيهم بكليات التربية جامعة المنصورة. أهمية البحث:

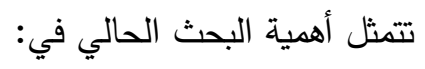
ا ـ. إن موضوع إدارة ضغوط العمل من الموضوعات المهمة التي تحتاج إلى إبرازها، لما لها من تأثير على أداء أعضاء هيئة التدريس ومعاونيهم.

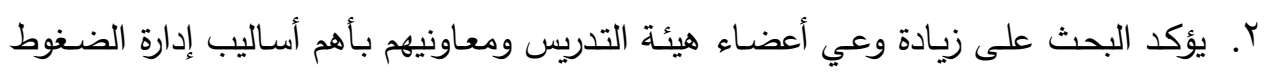
التي تواجههم ومصادر هذه الضغوط، والآثار السلبية الناتجة عنها. r. ق قد تفيد أعضاء هيئة التدريس ومعاونيهم في إدارة ضغوط العمل والتخلص من ضغوط التوط العمل

$$
\text { منهج البحث: السلبية. }
$$

ينطلق البحث الحالى بتعريف إدارة ضغوط عمل أعضساء هيئة التدريس ومعاونيهم بكليات

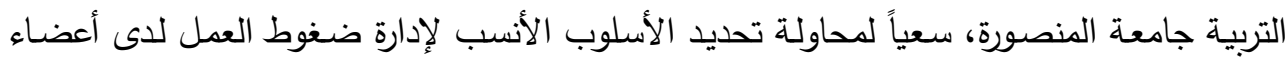
هيئة التدريس ومعاونيهم، وهذا يناسبه انتهاج المنهج الوصفي منهجاً للدراسة الحالية.

تمثلت أداة البحث في استبانة موجهة إلى بعض أعضساء هيئة التدريس ومعاونيهم بكليات

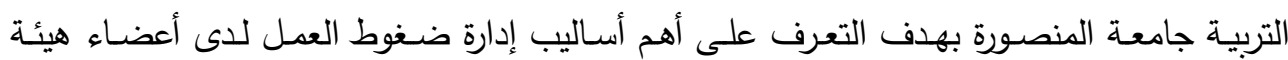
التدريس ومعاونيهم. مصطلح البحث:

\section{Work Stress Management}

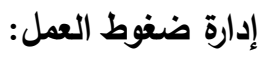

يعرفها البحث الحالى بأنها مجموعة من الأساليب التي يعتمد عليها أعضاء هيئة التدريس ومعاونيهم للتعامل مع العقبات التي تواجههم في بيئة العمل. لئل در اسات سابقة:

تم التوصل إلى مجموعة من الدراسات السابقة التي تتاولت ضغوط العمل، ما بين دراسات

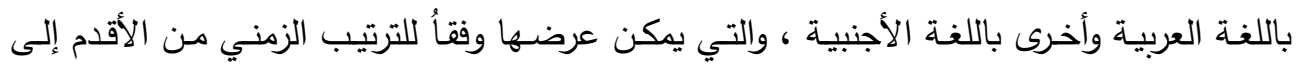

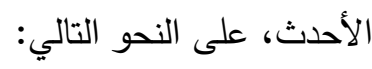


1- دراسة مقليديس و اسيمينوس (Michalidis\& Asimenos, 2002)، بعنوان أثر الدعم الاجتماعي على ضغوط عمل الأساتذة: هدفت إلى التعرف على ضغنوط العمل لاى أعضاء

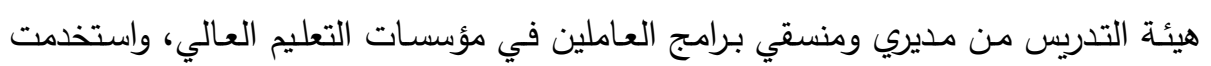

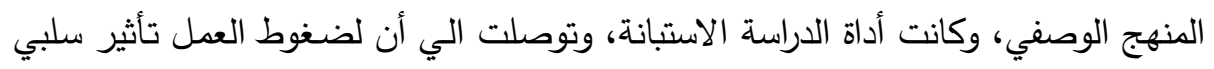

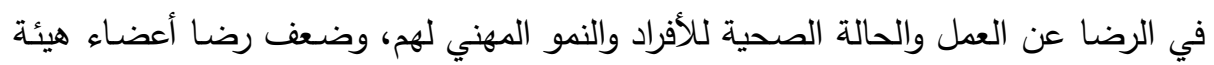

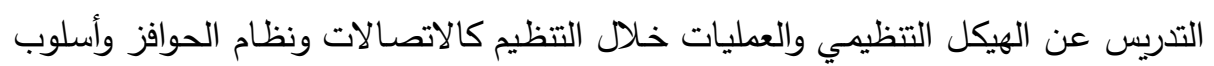
الإشراف ومدى المشاركة في اتخاذ القرارات.

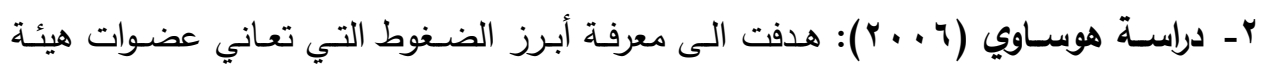

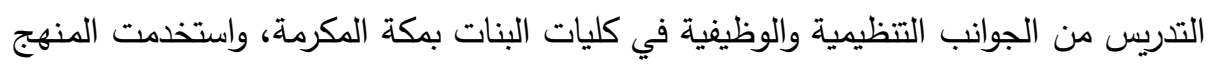

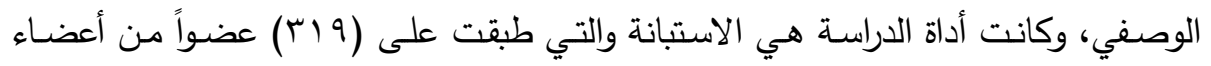

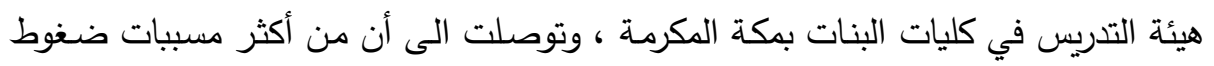

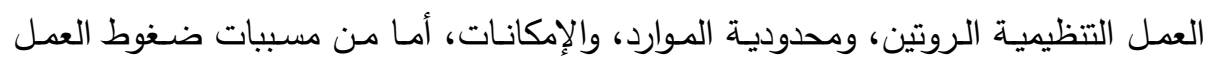

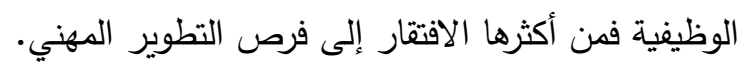

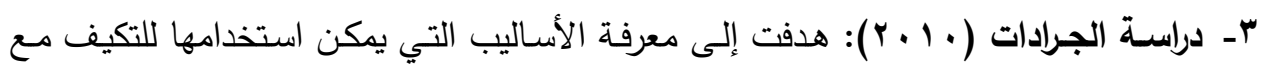

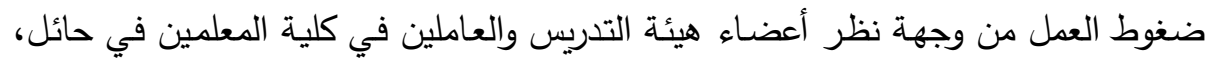
واستخدمت المنهج الوصفي، وكانت أداة الدراسة هي الاستبانة والتي طبقت على على عينة البحثي

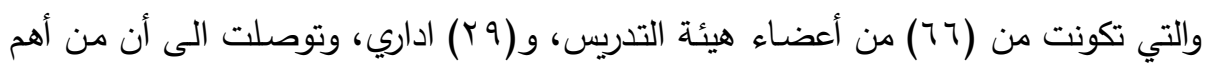

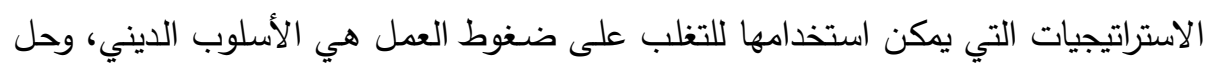
مشكلات العمل. ع - دراسة حمدان ( • ( ب): هدفت إلى معرفة مستوى ضغوط العمل لاى أعضاء هيئة التدريس

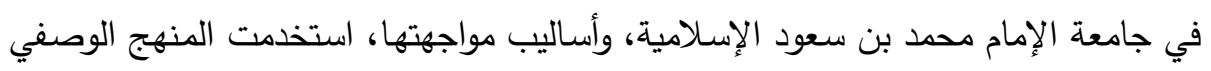

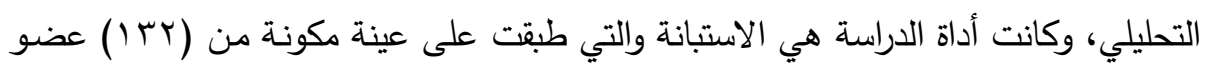
هيئة تدريس من الذكور والإناث من جامعة الامام محمد بن سعود الإسلامية، وتوصلت إلى الى الى

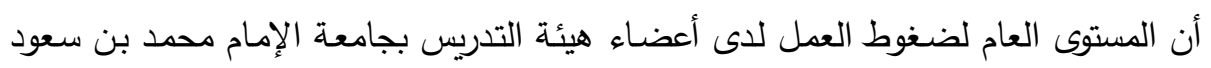

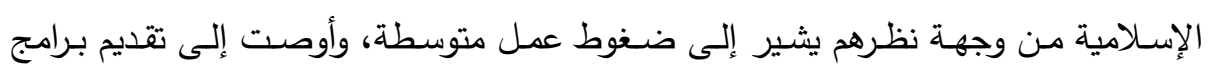
توعوية وتدريبية لمواجهة ضغوط العمل والحد من آثارها. 


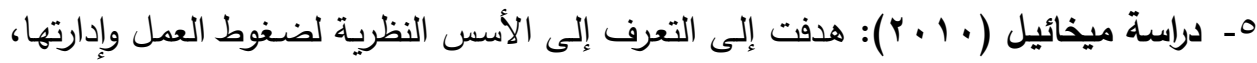

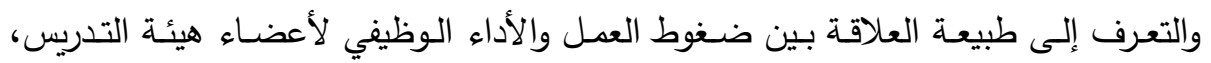
استخدمت المنهج الوصفي، وكانت أداة الدراسة هي الاستبانة والتي طبقت على على عينة مكونة

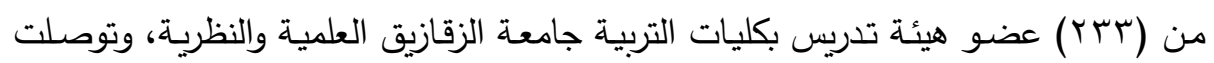

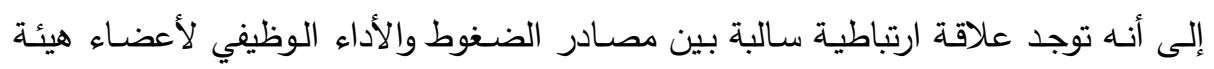

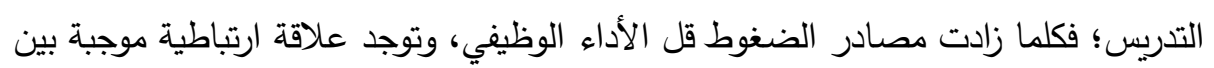

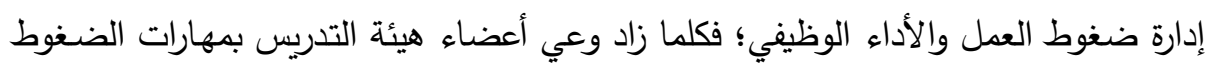
تحسن أدائهم الوظيفي.

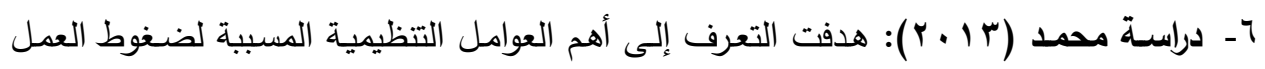

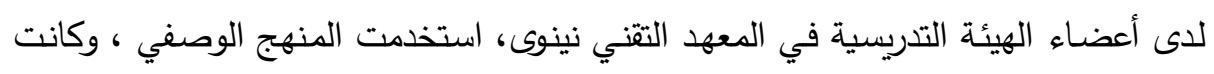

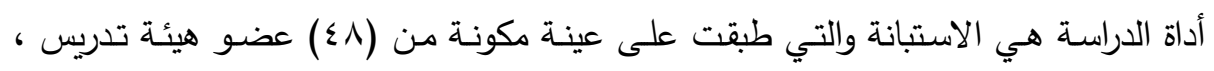

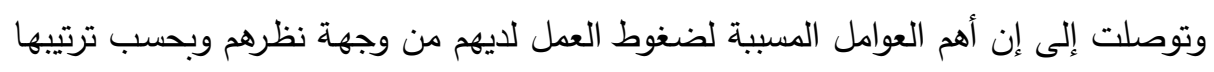

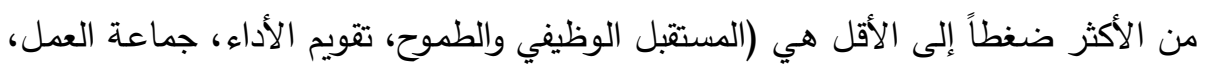

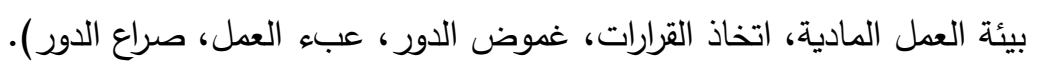

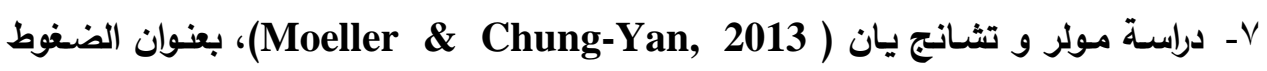
المهنية وعلاقتها بالتعليم العالي: هدفت إلى معرفة كيفية تفاعل أنواع مختلفة من الدعم

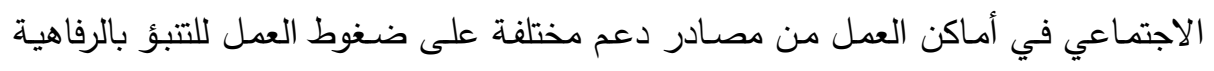
النفسية لأسـاتذة الجامعات، استخدمت المنهج الوصفي، وكانت أداة الدراسـة هي الاستبانة

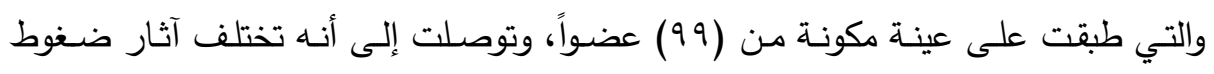

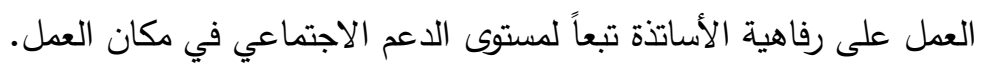

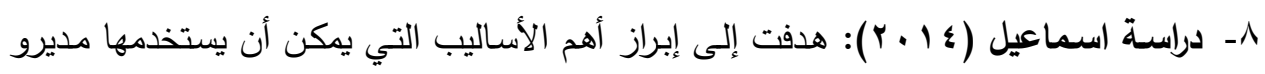

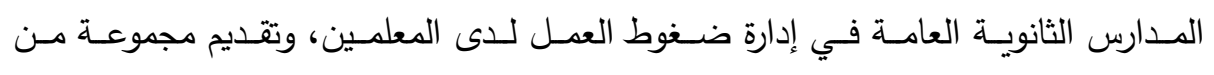

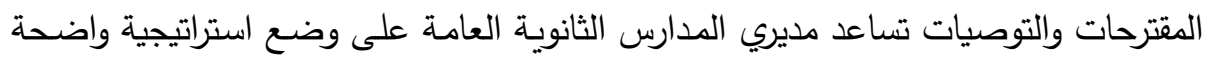
تفيد في معالجة ضغوط العمل لدى المعلمين، استخدمت المنهج الوصفي، وكانت أداة الدراسة

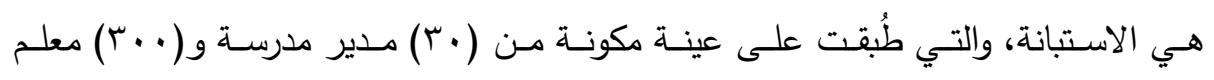

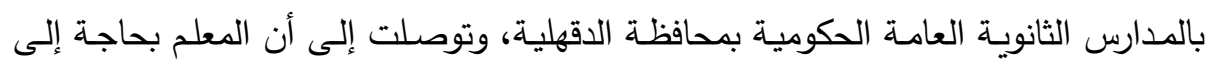
المسـاعدة في تطوير مهاراته والمشـاركة في عمليـة صنـع القرارات بالمدرسـة؛ فهذا يُشـعره 
بالراحة وبساطة العمل؛ مما يدفعه من جديد إلى الإنجاز ، وأوصت بضرورة توفير توصيف

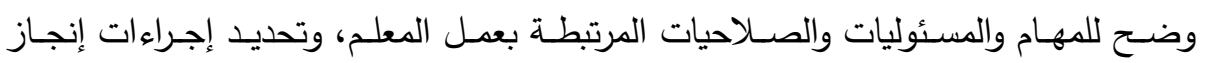

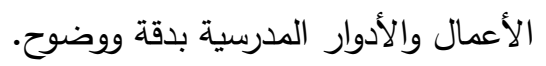

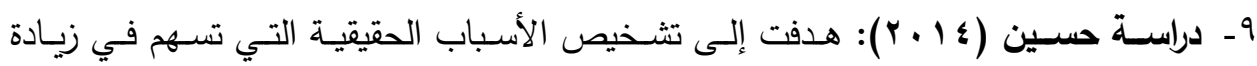

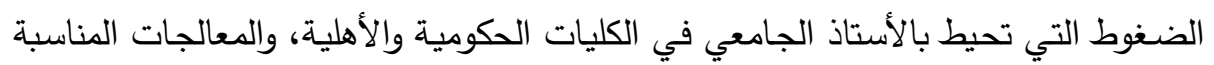

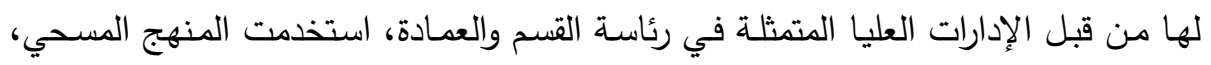

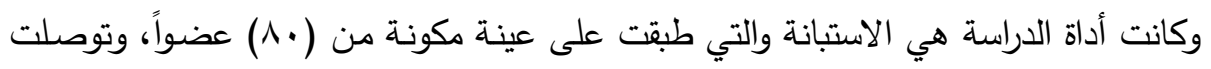

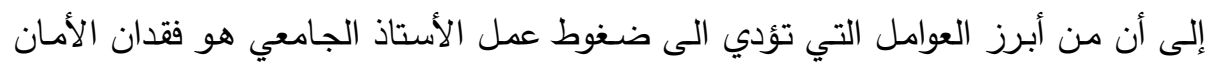

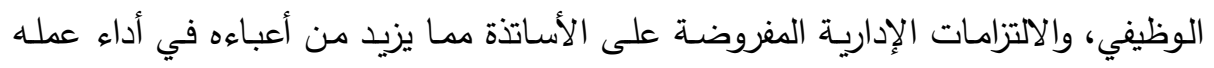
ويعيق نشاطه البحثي الإبداعي. التعليق على الدر اسات السابقة:

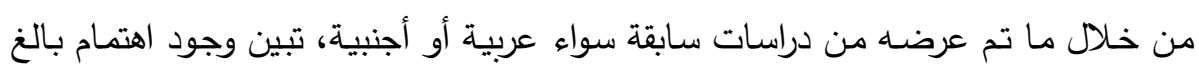
بإدارة ضغوط العمل، وضمان جودة البحث العلمي، ويمكن توضيح جوانب التثابه والاختلاف بين

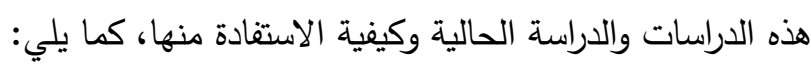

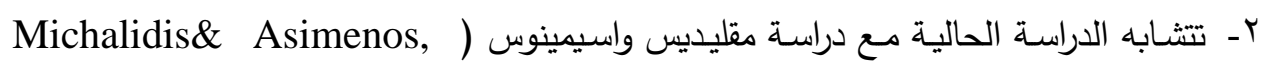

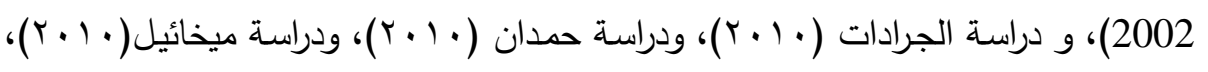

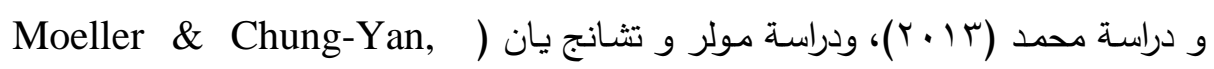

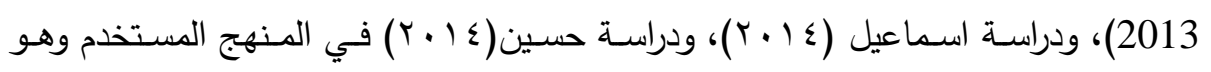
المنهج الوصفي، وأداة الدراسة وهي الاستبانة، وبعض نقاعل ودراط الاطار النظري.

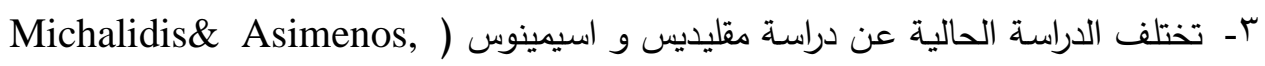

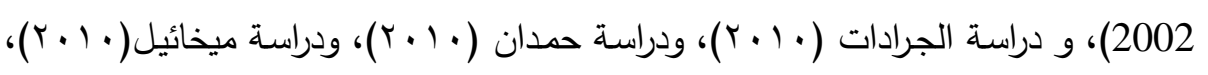

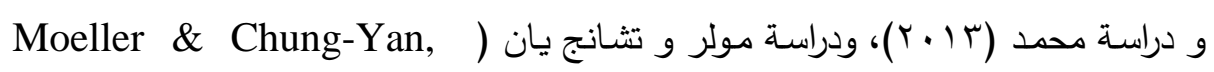

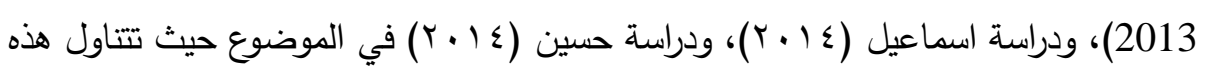

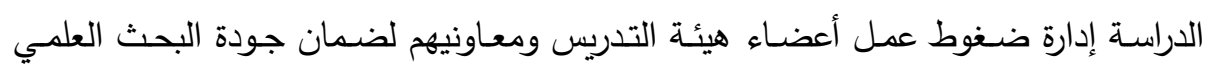
بكليات التربية جامعة المنصورة. 
استفاد البحث الحالي من الدراسات السابقة في تحديد المشكلة والمنهج المستخدم، وستستفيد في تكوين الاطار النظري الخاص بإدارة ضغوط العمل، حيث توضح الكثير من المصادر والمراجع المرتبطة بمتغيرات الدراسة.

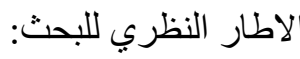

\section{Work Stress Management}

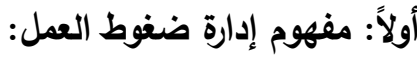

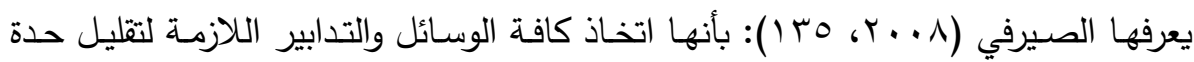
وكثافة الضغوط السلبية مع تعظيم الاستعادة من الضغوط الإيجابية، ويأتي ذلك من خلال متابعة

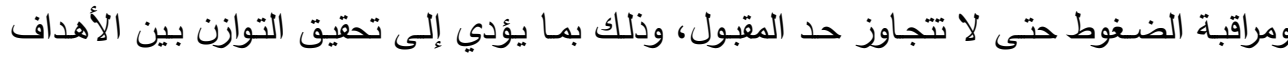
العامة التي تسعى إليها المنظمة وأهداف العاملين بها. كما يوضـح بيرك (Burke, 2013, 536) : بأنها التقليل من حدوث الضغوط والحد من لن اهن

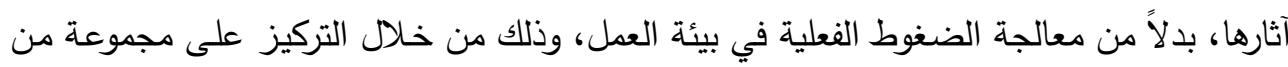

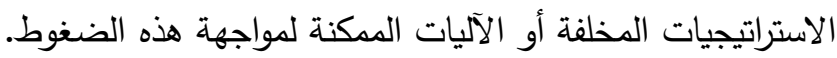

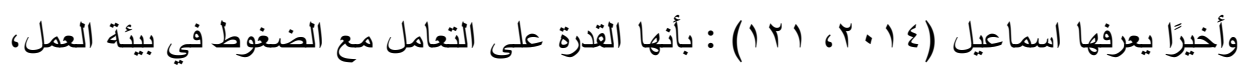

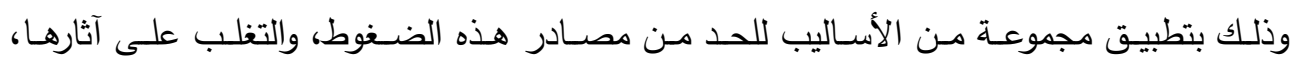

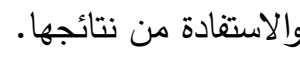
وفي ضوء ما سبق فإن البحث الحالي يعرفها إجرائياً بأنها: هي مجموعة من الأساليب التي

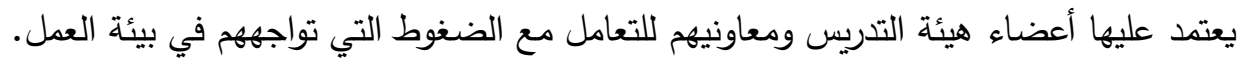

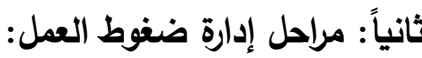
1- التعرف على مشكلة تتعلق بضغوط العمل: هي المرحلة التي يلعب فيها أعضاء هيئة التدريس ومعاونيهم من خلال مؤهلاتهم وإمكاناتهم التي يتمتعون بها، والتي تؤثر بشكل كبير على توجههم ومدى رؤيتهم للمشكلة، وكذلك رؤيتهم لماهية القرار المحتمل، ومن المهم توضيح أن عملية توصيف وتثخيص الوضع الراهن يعد مهارة

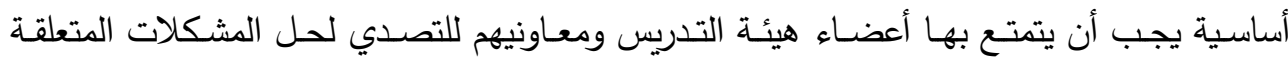

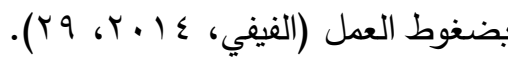
r- الكشف عن مسببات ضغوط العمل:

تهدف هذه المرحلة إلى التعرف على الأسباب والظروف التي أدت إلى ضـهور ضـغوط العمل التي تم وصفها في مرحلة الكشف عن التعرف على مشكلة تتعلق بضغوط العمل؛ وذلك من الن 
خلال الكثف عن المسببات التنظيمية والفردية لضغوط العمل؛ لإيجاد حلول مناسبة لها، من خلال

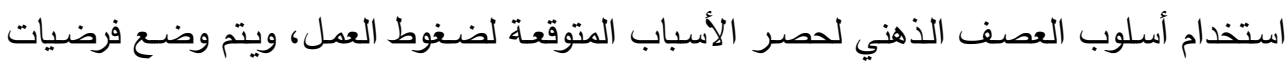

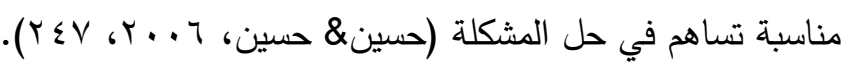

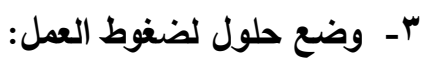

بعد التعرف على المشكلة وتفههها وتحديد أسبابها يتم تحديد الحلول المتوقعة والمحتملة التي يحتاجها أعضاء هيئة التدريس ومعاونيهم للثروع في إدارة ضغوط العمل، فقد تكون هذه الحلول من

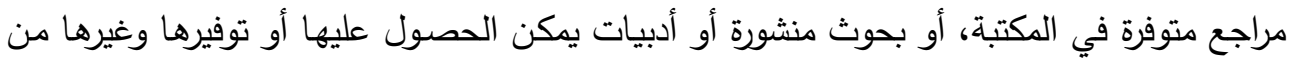
الأسـاليب المناسبة للوصـول لحلول مقترحة، وتتطلب بعض مشكرة فئلات ضـغوط العمل مواد وأدوات

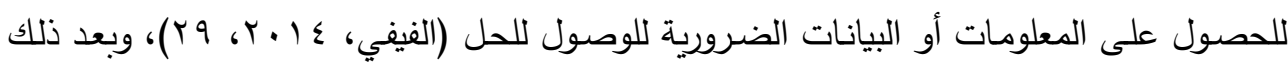
يتم اختبار الحلول المتوفرة للوصول إلى حل واضح، وتعد هذه المرحلة من أهم المراحل لأنها متعلقة

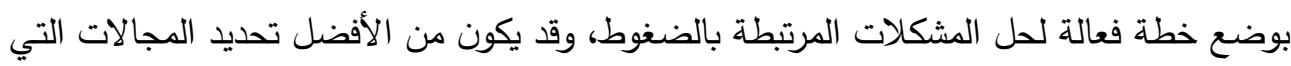

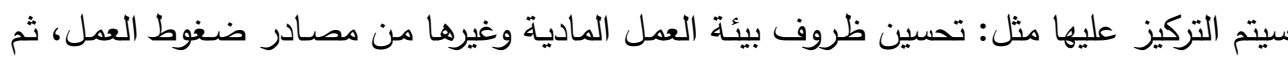

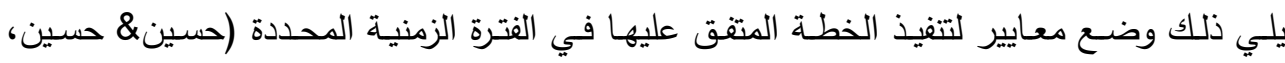
. ( $r \leq \Lambda, r . . T$

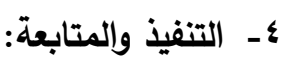

وفي هذه المرحلة يتوصل أعضاء هيئة التدريس ومعاونيهم إلى أن هناك عدة حلول لكل منها مزايا خاصة، وبعد مقارنة هذه الحلول على أساس معايير معينة يختار الحل الأفضل ويتم تطبيقه

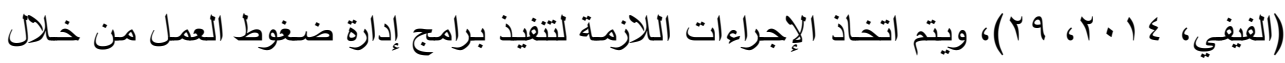

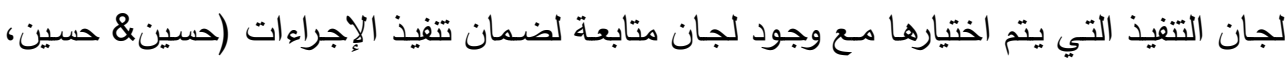

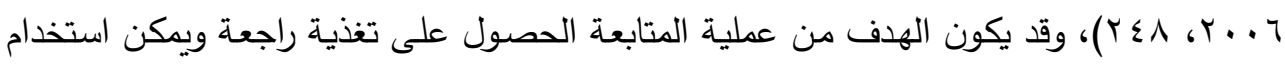
ما توصل إليه أعضاء هيئة التدريس ومعاونيهم من حقائق ومعلومات ثبت صندات صحتها في مواقف أخرى

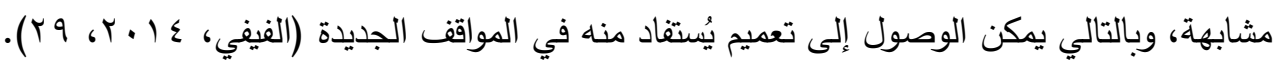

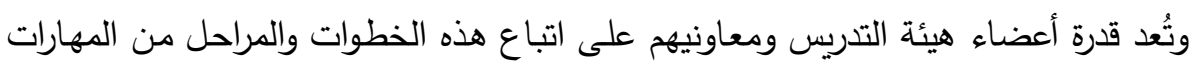
الأساسية التي يجب أن يتمتعوا بها للتوصل لحلول مناسبة للمواقف الضاغطة، وليس فقط اتباع هذه هذه

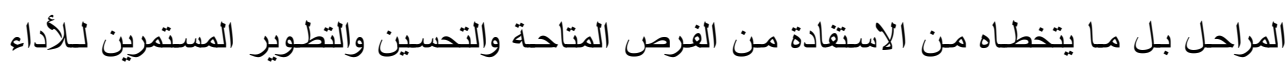
البحثي من أجل إدارة ضغوط العمل وبالتالي سينعكس على جودة البحث العلمي. ثالثاً: أساليب أعضاء هيئة التدريس ومعاونيهم في إدارة ضغوط العمل: 
تتعدد الطرق والأسـاليب التـي تسـاعد على التغلب على ضـغوط العهـل، والقضــاء على

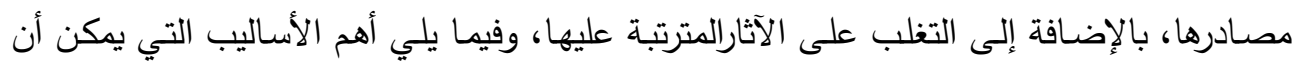

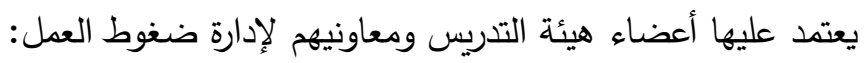
- توضيح المهام والأدوار الوظيفية لأعضاء هيئة التدريس ومعاونيهم:

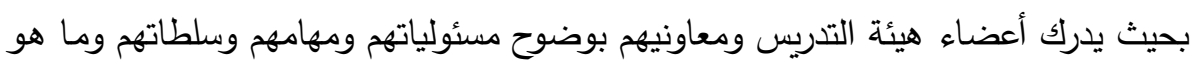

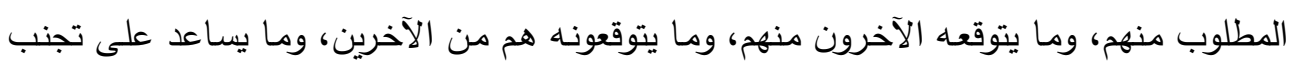

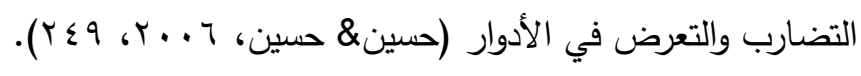

- إرشاد أعضاء هيئة التدريس ومعاونيهم وتوجيههم:

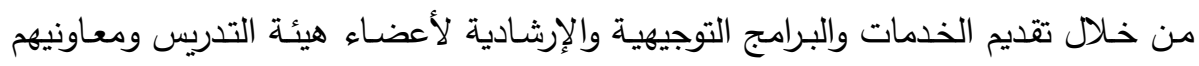
بقصد تحسين مستوى الصحة النفسية لديهم، وجعلهم يشعرون بالارتياح والقدرة على تحقيق جودة

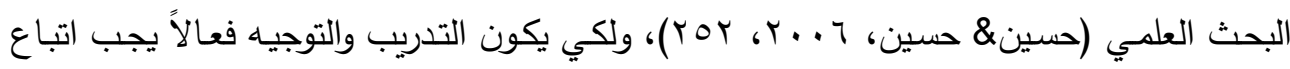
أسلوب نظامي يتكون مع عدة خطوات هي: أ) تحديد الاحتياجات وأهداف التدريب والتوجيه. ب) تطوير معايير التدريب.

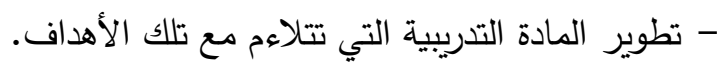

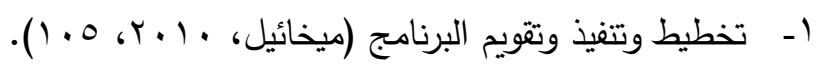

- تفويض السلطة لأعضاء هيئة التدريس ومعاونيهم: يعتبرالتفويض عمليـة حساسـة؛ لأنها تتطلب تخويـل المسئولية والسـلطة مـع بقـاء الالتزام

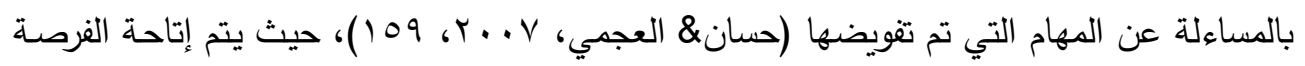

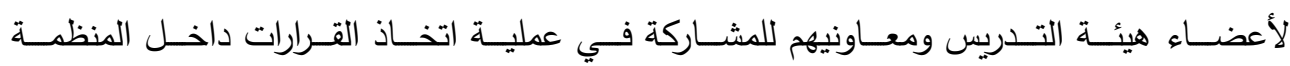

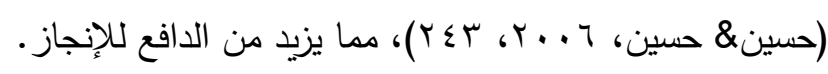

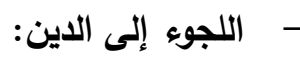

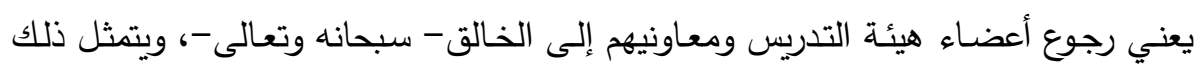

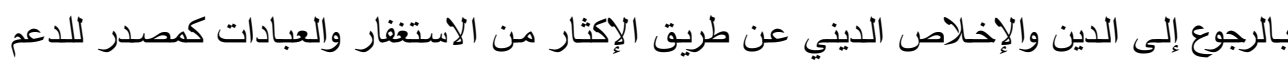

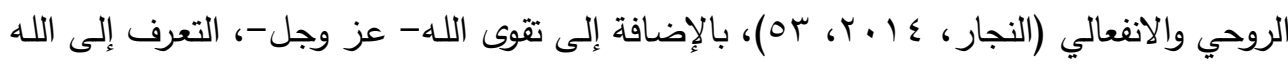

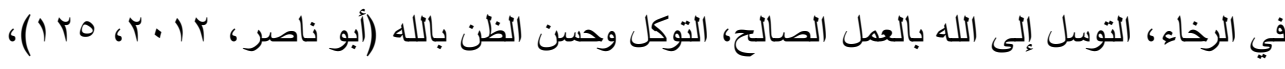

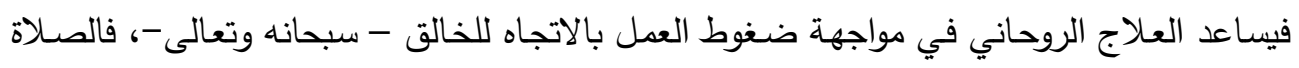


تضفي على النفس هدوء وسكينة، والدعاء إلى المولى - عز وجل- يخفف عن أعضـاء هيئة

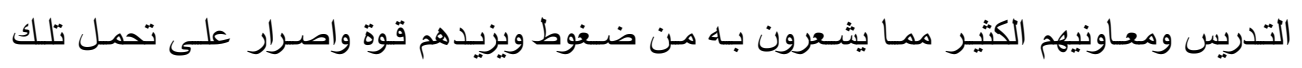

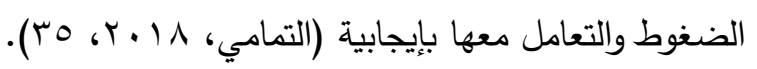

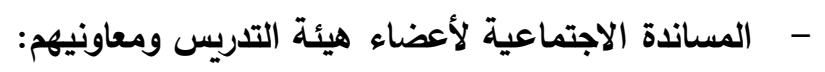

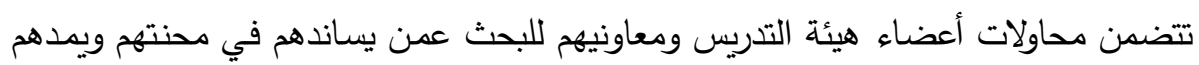
بالتوجيه للتعامل مع الأحداث الضـاغطة، والمساعدة لمواجهة هذه الأحداث بصورة أكثر إيجابية،

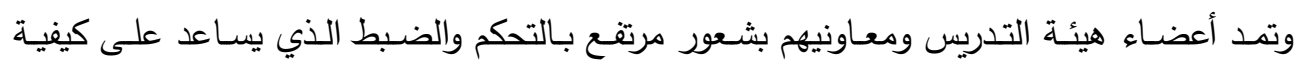

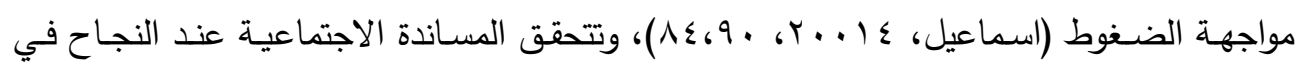

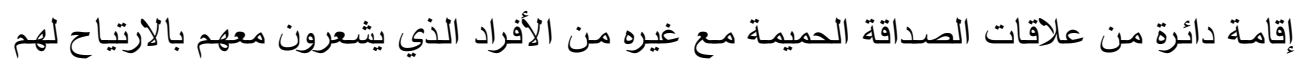

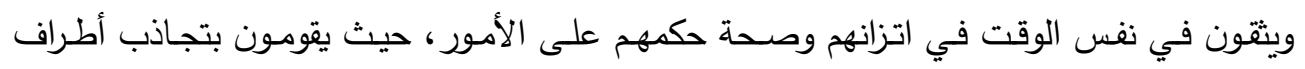

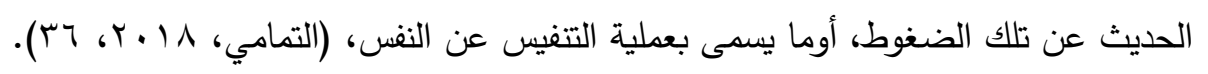

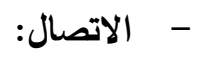

ينبغي أن يكون التواصل إيجابي من خلال قنوات مفتوحة وواضحة تساعد على التواصل بين

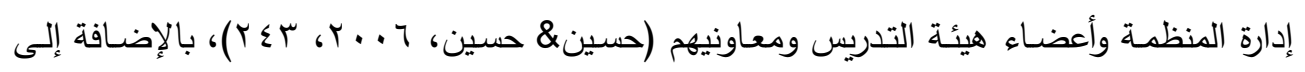
نقل المعلومات والأسس والقواعد بشكل تعاوني، وتتمية اتجاهاتهم الإيجابية نحو الإنجاز والبحث

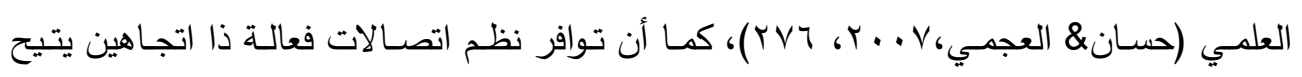

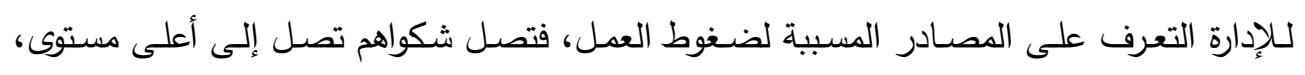

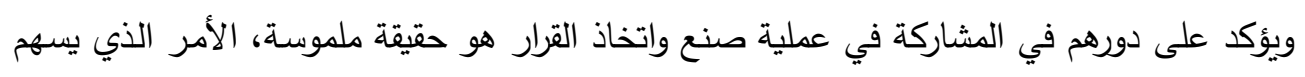

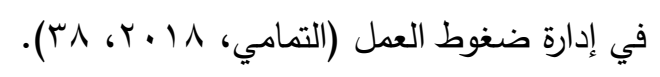

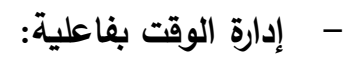

تعني التحكم في الوقت واستثماره بالثكل الذي يحقق لأعضـاء هيئة التدريس ومعاونيهم

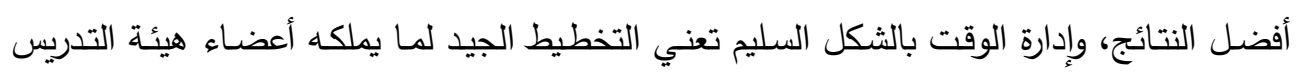
ومعاونيهج من وقت وطاقة لتحقيق جودة البحث العلمي، وتوظيف ما يمتلكونه من إمكانات مادية

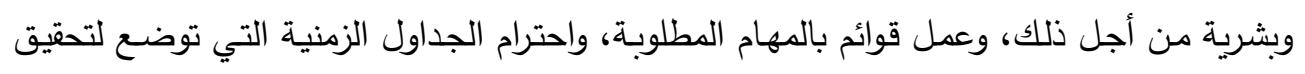

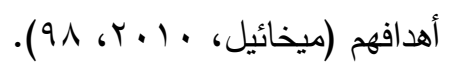
- تحسين بيئة العمل المادية: 
تثكل بيئة العمل المادية جزء مهم من حياة أعضاء هيئة التدريس ومعاونيهج؛ لذا فإن العناية

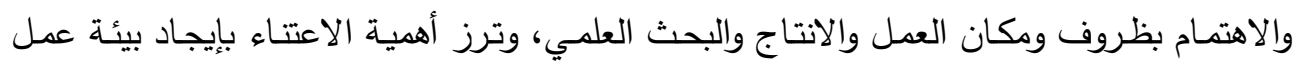

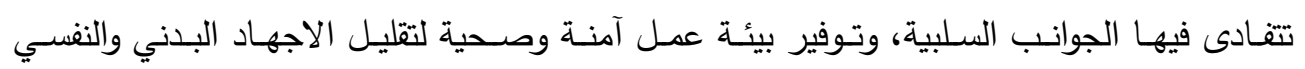

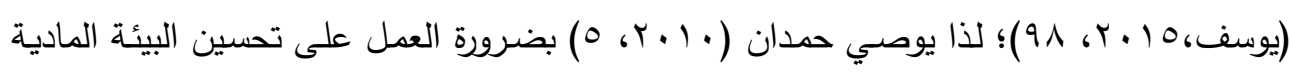

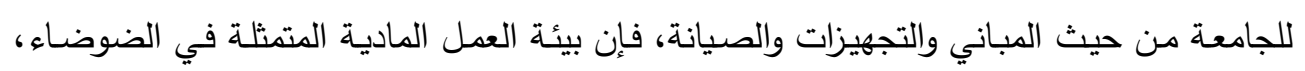
الحرارة، الإضاءة والتلوث تعد من مصادر ضغوط العمل التي ينبغي مواجهتها والتغلب عليها، من

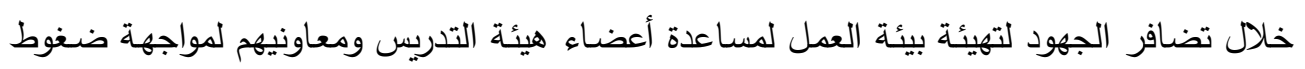
العمل وتحقيق جودة البحث العلمي.

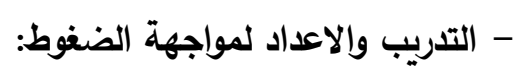

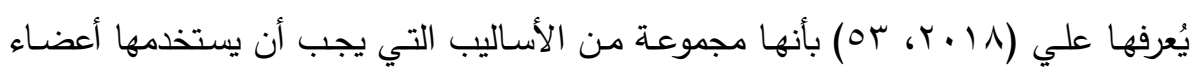

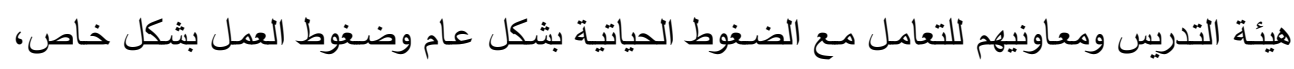

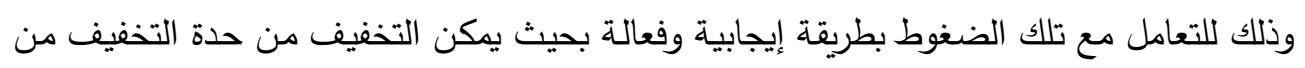
حدة تلك الضغوط وتلافي آثارها السلبية عليهم.

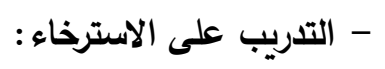

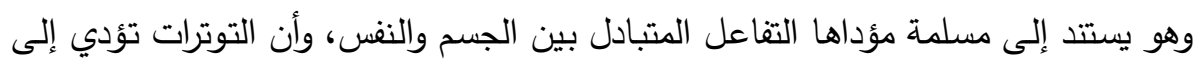

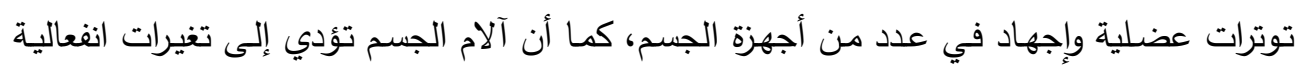

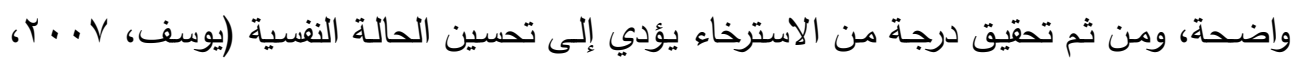

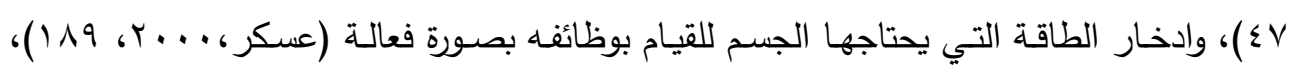

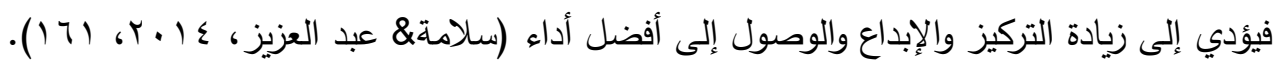
- إعادة تصميم الهيكل التنظيمي:

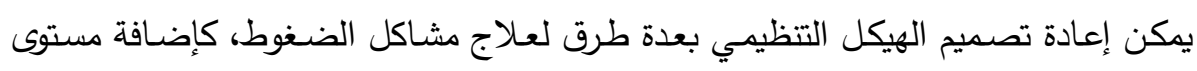

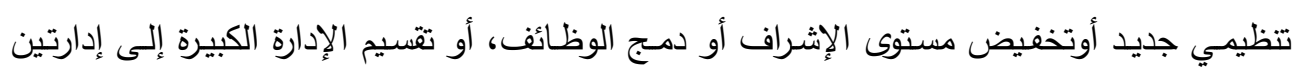

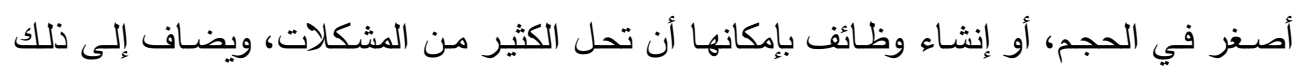

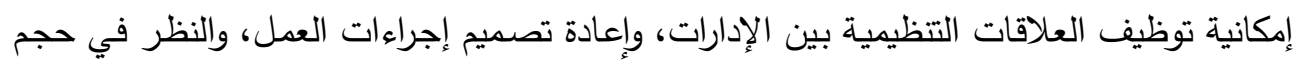

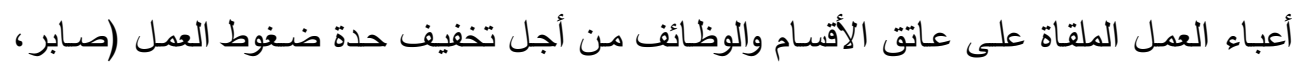
$\cdot(1 \leq \cdot 6 \cdot) \leq$ - نظم الحوافز وتقييم الأداء: 


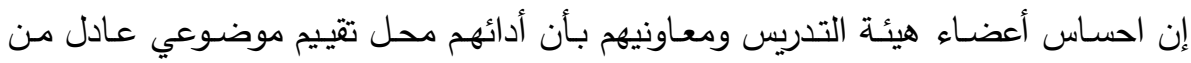

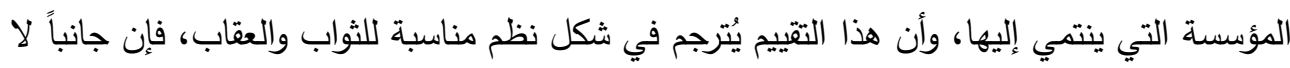

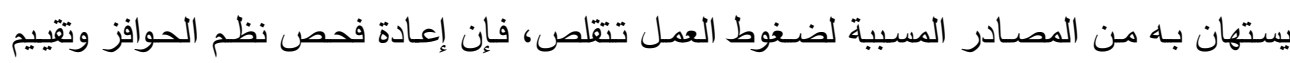
الأداء على فترات دوريـة مناسبة للتأكد من تحقيق هذه النظم بعدالة وموضوعية يعتبر استراتيجية

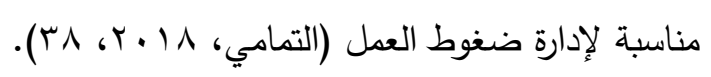

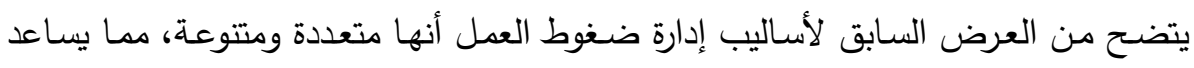
أعضاء هيئة التدريس ومعاونيهم اختيار الأسلوب المناسب للتخلص من ضغوط العمل، فإن القدرة

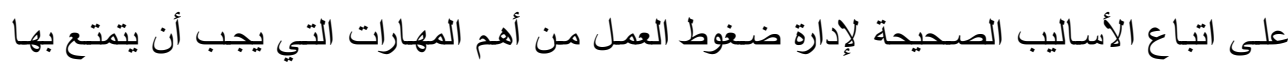

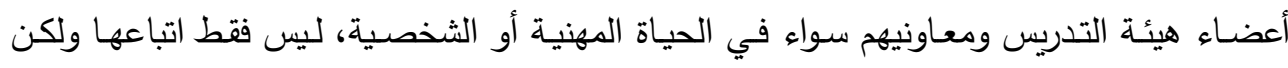
التحسين والتطوير لهذه المراحل وذلك لاتخاذ القرارات السليمة التي تقيد الارتقاء بأدائه. إجراءات الدر اسة الميدانية: أولاً: أهداف الدراسة:

تهدف الدراسـة الحالية إلى استطلاع رأي أعضـاء هيئة التدريس ومعاونيهم بكليات التربية

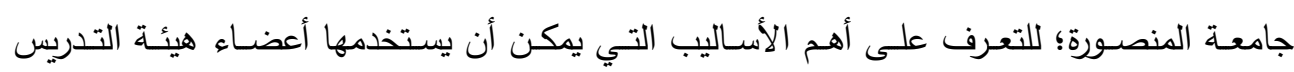
ومعاونيهم في إدارة ضغوط العمل.

ثانيًا: أداة الدراسة: في ضوء الأهداف التي تسعى إليها الدراسة الميدانية، تم تصميم استبانة اشتملت على أربعة

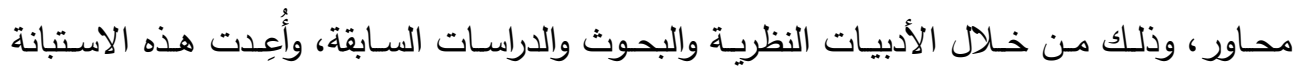
بالطريقة المقيدة المفتوحة، وفق الخطوات التالية: - تحديد أساليب أعضـاء هيئة التدريس ومعاونيهج في إدارة ضغنوط العمل بكليات التربية جامعة المنصورة. - تحديد مجموعة من العبارات، حيث يطلب من المستجيب أن يضع علامة (ل أمام الاستجابة التي تعبر عن درجة توافرها بدرجة ( كبيرة جدًا- كبيرة- متوسطة- ضعيفة- ضعيفة جدًا). 
- تم عرض الاستبانة في صورتها المبدئية على مجموعة من السادة المحكمين من إساتذة كليات

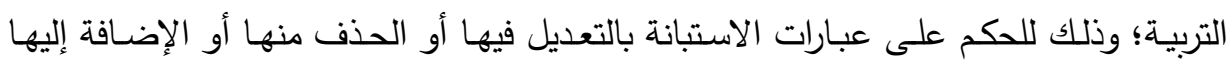

$$
\text { وصلاحيتها للتطبيق، وجاءت بعض التعديلات بها. }
$$

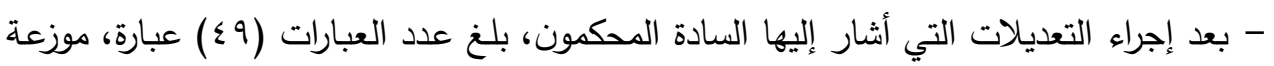

$$
\text { كالتالي: }
$$

1- المحورالأول: أسـاليب إدارة ضـغوط العمل التتظيميـة للدى أعضـاء هيئة التدريس ومعـاونيهم

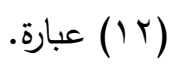

r- المحورالثاني: أسـاليب إدارة ضـغوط العمل الوظيفيـة لدى أعضـاء هيئة التدريس ومعـاونيهج

$$
\text { ( ب) }
$$

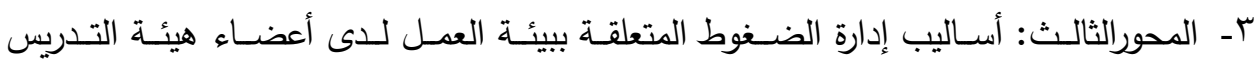

$$
\text { ومعاونيهم (r ا ( ) عبارة. }
$$

ع- المحور الرابع: أساليب إدارة ضغوط العمل الثخصية لدى أعضاء هيئة التدريس ومعاونيهم

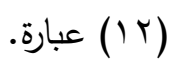

وفي نهاية كل محور عبارة مفتوحة حتى تتاح الفرصـة للمستجيبين لإضـافة ما يرونه مناسبًا من أساليب من وجهة نظرهم.

\begin{tabular}{|c|c|c|}
\hline معامل ألفا (معامل الثبات) & عدد العبارات & المحور \\
\hline •,ATV & ir & الأول \\
\hline •, & ir & الثاني \\
\hline$\cdot, v \leqslant r$ & $1 \pi$ & الثالث \\
\hline$\cdot, \vee \vee \neg A$ & ir & الرابع - ل ابع \\
\hline - & $\leq 9$ & الاستبانة ككل \\
\hline
\end{tabular}

- تـم حسـاب ثبـات الاسـتبانة، وذلـك باسـتخدام برنـامج الـرزم الإحصـائية للعلـوم الاجتماعيـة Statistical Package for Social Sciences (SPSS)v.21 ألفا كرونباخ، والجدول ( ) التالي يوضح قيمة معامل ألفا كرونباخ لقياس ثبات الاستبانة:

جدول (1)

قيم معاملات ثبات "ألفا" للمحاور الفرعية والاستبانة ككل جلول 


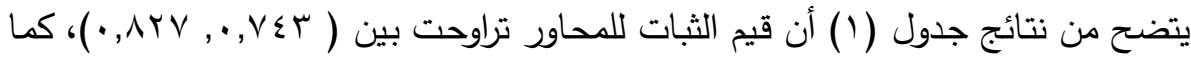

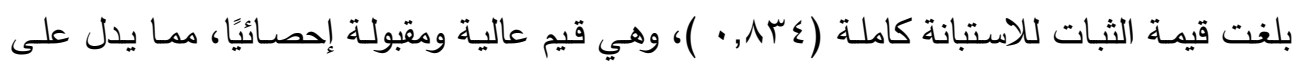
ثبات الاستبانة وأنها صالحة للتطبيق. ثالثًا: عينة الاراسة:

تم تطبيق الاستبانة على عينة ممثلة من أعضـاء هيئة التدريس ومعاونيهم بكليات التربية

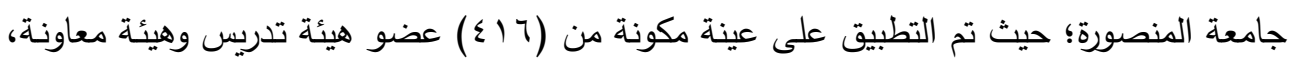

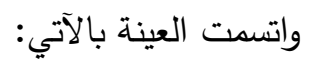

ا - تجمع بين النوع الذكور والإناث؛ حيث بلغ عدد الذكور في عينة البحث (بـ ( ) ذكرًا بنسبة

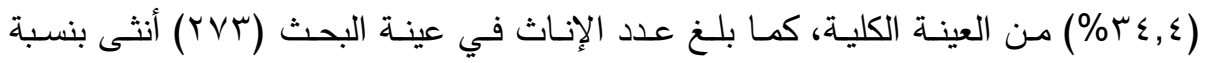

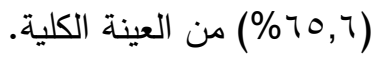

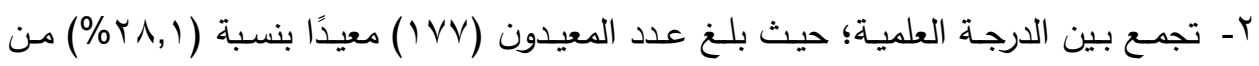

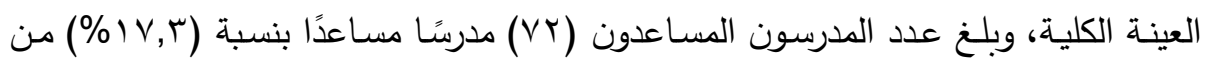

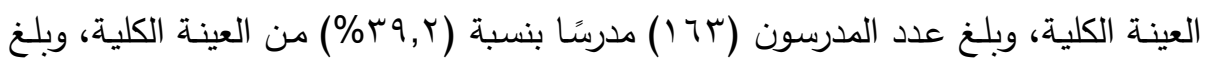

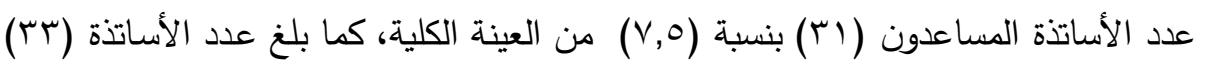
أستاذًا بنسبة (V,9) من العينة الكلية.

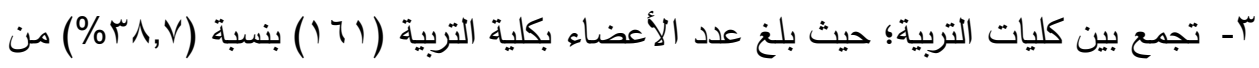

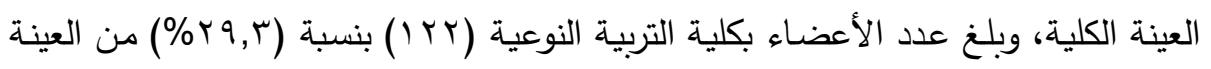

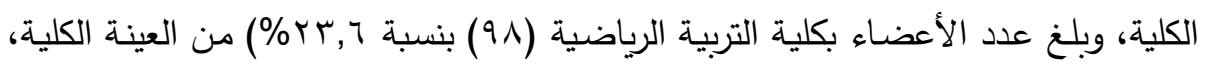

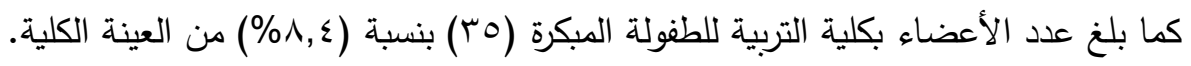
رابعًا: المعالجة الإحصائية للبيانات:

تمــت المعالجــة الإحصــائية باســتخدام برنــامج الــرزم الإحصــائية للعـــوم الاجتماعيــة Statistical Package for Social Sciences (SPSS)v.21) لكل عبارة موزعة على تكرارات الاستجابات (كبيرة جدا- كبيرة- متوسطة- ضعيفة- ضعيفة جدا)

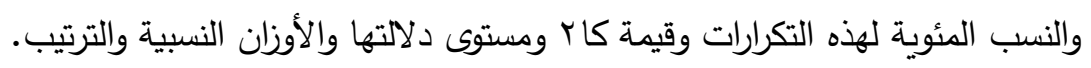
خامسًا: نتائج الدراسة الميدانية نتائج المحور الأول: أسـاليب إدارة ضغوط العمل التظظيمية لدى أعضـاء هيئة التدريس ومعاونيهم: 
نظراً لوجود فروق ذات دلالة احصائية عينة الدراسة وفقاً للنوع والدرجة العلمية والكلية حول أساليب إدارة ضغوط العمل التتظيمية لدى أعضاء هيئة التدريس ومعاونيهج، سيتم توضيح استجابات كلا منها على حده، كما هو موضح بالجدول التالي: جدول (r)

استجابات عينة الاراسة وفقاً للنوع حول أساليب إدارة ضغوط العمل التنظيمية لاى أعضاء هيئة التدريس ومعاونيهم (ن= 17 ( ) )

\begin{tabular}{|c|c|c|c|c|c|c|c|c|c|c|c|c|c|c|c|c|c|}
\hline \multirow{3}{*}{ سلدالةق } & \multirow{3}{*}{ قيدة كام } & \multicolumn{7}{|c|}{ الإناث (YVr) } & \multicolumn{7}{|c|}{ النكور (1:T) } & \multirow{3}{*}{\multicolumn{2}{|c|}{ العبارات }} \\
\hline & & \multirow[b]{2}{*}{ الترتيب } & \multicolumn{6}{|c|}{ البائلن } & \multirow[b]{2}{*}{ يب الترن } & \multirow[b]{2}{*}{ النبيني } & \multicolumn{5}{|c|}{ 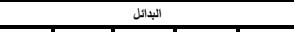 } & & \\
\hline & & & التببي & ضعيفة هاً & ضعيفة & متوسطة & كبيرة & كبيرة & & & ضبأ & ضعيفة & متوسطة & كبيرة & كبيرة & & \\
\hline \multirow{2}{*}{., .0} & \multirow{2}{*}{ 1., ros } & \multirow{2}{*}{, } & \multirow{2}{*}{., 007} & $\leqslant$ & 19 & :0 & 15 & $\times 9$ & \multirow{2}{*}{ '. } & \multirow{2}{*}{. } & 1. & $\$$ & iv & $r A$ & $r \xi$ & 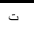 & \\
\hline & & & & 17,1 & $\Gamma \varphi, r$ & 19,0 & $r r, \varepsilon$ & $\frac{1,1,1}{1}$ & & & $\frac{v}{v}$ & $r \cdot, \Lambda$ & $1 \times, 9$ & $r q, 4$ & $17, \Lambda$ & $\%$ & \\
\hline \multirow{2}{*}{., } & \multirow{2}{*}{$r r, q \leqslant r$} & \multirow{2}{*}{$v$} & \multirow{2}{*}{.019} & $\leadsto$ & a) & $\leqslant 9$ & or & is & \multirow{2}{*}{ ir } & \multirow{2}{*}{ דיר, } & 17 & rv & $\mathrm{rv}$ & $\leqslant 9$ & if & $=$ & \multirow{2}{*}{ r } \\
\hline & & & & $r 1, r$ & $r r, r$ & $1 v, 9$ & $r \cdot, 9$ & 9,7 & & & $11, r$ & $1 \wedge, 9$ & $r 0,9$ & $r \xi, r$ & $9, \Lambda$ & $\%$ & \\
\hline \multirow{2}{*}{,., 1} & \multirow{2}{*}{$r, r r$} & \multirow{2}{*}{ م. } & \multirow{2}{*}{., 0.4} & זי & ar & $r \lambda$ & or & $r$ & , & r. & iv & ri & r. & os & ir & 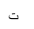 & r. \\
\hline & & & & $\overline{Y \xi, Y}$ & $r r, y$ & $1 r, 9$ & $r+9$ & $\frac{\gamma, r}{r}$ & & , & 11,9 & $\overline{M, Y}$ & "n & 80,7 & $\lambda, \xi$ & $\%$ & \\
\hline 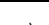 & $r y$ & 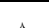 & (1) & $\pi$ & 9.1 & $\$$ & 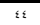 & 79 & 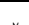 & 2. & "I & $m$ & $\pi$ & 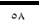 & 10 & $ت$ & 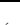 \\
\hline , & $r v, q r$ & $\wedge$ & 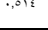 & $r r, r$ & $r 0,9$ & 10 & 19,1 & 10,2 & v & 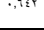 & $\overline{v, v}$ & $r 0, r$ & 19,1 & $\$,, 4$ & $1 \cdot, 0$ & $\%$ & \\
\hline & & & & $\leqslant 9$ & 4. & $r$ & 18 & $r$ & & & $r$. & $\pi$ & $1:$ & so & $r r$ & ت & \\
\hline , & 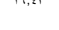 & $r$ & , & $v, q$ & $r 0,9$ & $11, \varepsilon$ & $r r, \xi$ & $11, \varepsilon$ & 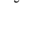 & 年 & Is & $r r, \xi$ & $9, \AA$ & $r 1,0$ & $r r, \xi$ & $\%$ & \\
\hline 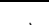 & $r \in g r$ & ir & . & $n$ & $\Delta V$ & $\$$ & or & 19 & 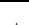 & $\pi$ & ir & $r_{\lambda}$ & $r$. & $\pi$ & it & $ت$ & 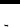 \\
\hline (,.) & $F_{i, 4 i}$ & 18 & 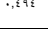 & $\overline{r T}$ & $r 1,9$ & 17,4 & 19,8 & 0,9 & 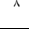 & 0,718 & $\overline{\lambda, \mathrm{\varepsilon}}$ & $m, i$ & $1:$ & $\{r$ & 9,1 & $\%$ & \\
\hline$\ldots$ & $r ., 0 m$ & $\therefore$ & or & 70 & $\Delta r$ & ro & $\pi$ & $r v$ & $r$ & גיר & in & $\overline{r i}$ & ra & $m$ & $m$ & $ت$ & y \\
\hline , & 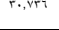 & ${ }^{\circ}$ & , or & $r r, \Lambda$ & $F, \xi$ & $1 \%, \Lambda$ & $r r, 1$ & 9,9 & & 年, & 18,7 & 19,4 & $r \cdot, r$ & ro, & $r o, r$ & $\%$ & $\checkmark$ \\
\hline 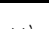 & 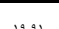 & , & 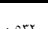 & .09 & $4 r$ & $r r$ & $\pi$ & rv & 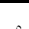 & opr & ir & i. & iv & $\leqslant r$ & $r$. & $ت$ & 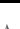 \\
\hline (,.) & $14,4 !$ & ; & , & $r 1, r$ & $r r, v$ & $1 \%, 1$ & $r r, Y$ & 9,9 & $e^{\circ}$ & , tor & 4,1 & $r A$ & 11,9 & $r \cdot,+$ & $n$ & $\%$ & \\
\hline 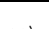 & $r$. & . & - & "11 & 1.9 & $r T$ & 59 & ro & 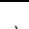 & & ir & $m$ & "1 & $r \leqslant$ & 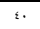 & $ت$ & . \\
\hline , & 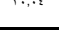 & 1. & 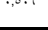 & $r r, r$ & $r \mathrm{rA,A}$ & $11, y$ & $\mid v, 9$ & $9, r$ & & nin & $\lambda, \delta$ & $r_{0, r}$ & 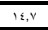 & $r r, \lambda$ & $r \wedge$ & $\%$ & \\
\hline 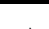 & & & & 04 & 14 & $\$ 1$ & 00 & $r$. & 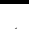 & 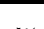 & 10 & $r_{0}$ & $r$. & 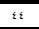 & 79 & $ت$ & , \\
\hline ,., & $1 \alpha, 74$ & $r$ & , & $r_{r, 0}$ & {$[1,0$} & $17, \lambda$ & $r \cdot, 1$ & " & ; & 年 & 1,0 & $\gamma\{, 0$ & 18 & $r \cdot, \lambda$ & $r \cdot r$ & $\%$ & . \\
\hline 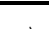 & 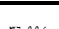 & - & r & or & $9 \xi$ & $0 \leqslant$ & or & 19 & $x$ & 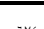 & 1. & $r q$ & $\overline{r y}$ & or & $r_{0}$ & $ت$ & 7 \\
\hline 年, & $\Gamma 7,998$ & 1 & r,or & 19 & $r_{t, \varepsilon}$ & 19,1 & $r_{r, q}$ & 0,9 & $r$ & 列, & $y^{\prime}$ & $r \cdot r$ & $1 \wedge, 9$ & $r_{T, \delta}$ & $1 v, 0$ & $\%$ & , \\
\hline & & & & 87 & 1.9 & $r_{0}$ & 09 & iv & & & 19 & $r$ & $1 \mathrm{in}$ & 09 & 17 & $ت$ & \\
\hline , & ${ }^{\top 1,}, \mathrm{YAT}$ & 9 & $0,0 \cdot 4$ & $r ., 0$ & $r_{A, A}$ & $r \varphi, \lambda$ & $r 1, r$ & $7, r$ & ${ }^{4}$ & o, & $\mid r, r$ & $r, v$ & 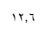 & $\{1, r$ & $11, r$ & $\%$ & r \\
\hline
\end{tabular}

يتضح من الجدول السابق ما يلي:

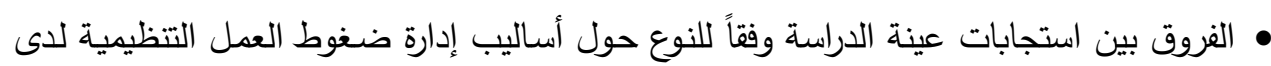

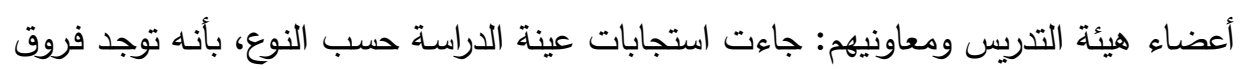

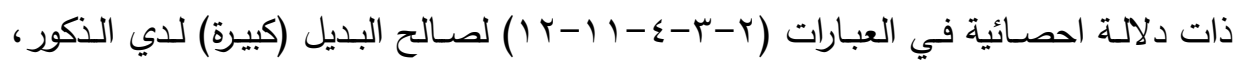

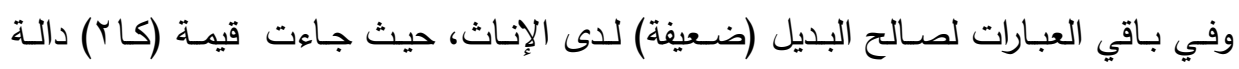

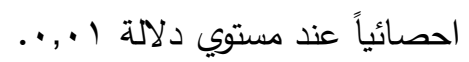
نتائج المحور الثاني: أسـاليب إدارة ضـوط العمل التول الوظيفية لدى أعضاء هيئة التدريس ومعاونيهم: 
نظراً لوجود فروق ذات دلالة احصائية عينة الدراسة وفقاً للنوع والدرجة العلمية والكلية حول

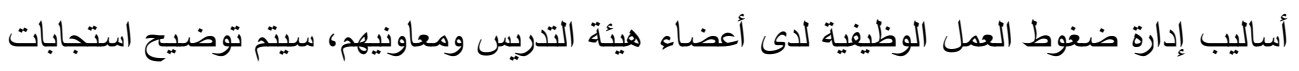

$$
\text { كلا منها على حده، كما هو موضح بالجدول التالي: }
$$

جدول (r)

استجابات عينة الدراسة وفقاً للنوع أساليب إدارة ضغوط العمل الوظيفية لدى أعضاء هيئة

التدريس ومعاونيهم (ن= 7 أغ ؛ )

\begin{tabular}{|c|c|c|c|c|c|c|c|c|c|c|c|c|c|c|c|c|c|}
\hline \multirow{3}{*}{ مستوى } & \multirow{3}{*}{ كان } & \multicolumn{7}{|c|}{ الإناث (T/Y) } & \multicolumn{7}{|c|}{ الأكور (ז٪؛ 1) } & \multirow{3}{*}{\multicolumn{2}{|c|}{ العبارات }} \\
\hline & & \multirow[b]{2}{*}{ الترتيب } & \multicolumn{6}{|c|}{ البدائل ل بائل } & \multirow[b]{2}{*}{ الترتيب } & \multirow[b]{2}{*}{ النسبي } & \multicolumn{5}{|c|}{ البدائل } & & \\
\hline & & & النسبي & فة جداً & ضة ضعي & متوسطة & كبيرة & جيأ & & & فة جـاً & ضة ضعي & متوسطة & كبيرة & كبيرة & & \\
\hline \multirow{2}{*}{.,$\cdot 1$} & \multirow{2}{*}{$r \leq, Y O T$} & \multirow{2}{*}{11} & \multirow{2}{*}{$\cdot, 0 \cdot 1$} & v. & $\Delta T$ & $\varepsilon$ & ז & iv & \multirow{2}{*}{ "1 } & \multirow{2}{*}{ צדו, } & iv & Tr & in & or & is & ت & \multirow{2}{*}{1} \\
\hline & & & & $r 0,1$ & $r \cdot, \varepsilon$ & $1 \leqslant, Y$ & $r, 1$ & 7,4 & & & 11,9 & $r r, 1$ & $1 Y, 4$ & $r 9,9$ & $1 r, 7$ & $\%$ & \\
\hline \multirow{2}{*}{,., 1} & \multirow{2}{*}{ r५, १९० } & \multirow{2}{*}{ v } & \multirow{2}{*}{., 011} & 0. & 99 & or & 01 & $1 \leqslant$ & \multirow{2}{*}{1} & \multirow{2}{*}{ •, 77 A } & $\wedge$ & ro & rA & @o & rv & ت & \multirow{2}{*}{$r$} \\
\hline & & & & $1 A, r$ & $r 4, r$ & 19 & $r, Y$ & 0,1 & & & 0,7 & $r \leqslant, 0$ & 19,7 & $r 1,0$ & $1 \wedge, 9$ & $\%$ & \\
\hline \multirow{2}{*}{,., 1} & \multirow{2}{*}{ IA,YVY } & \multirow{2}{*}{ r } & & ir & rr & 00 & $\pi$ & r" & & - & ir & ro & rA & $\varepsilon r$ & $r \leqslant$ & ت & $r$ \\
\hline & & & . & $r r, Y$ & $r \uparrow, \varepsilon$ & $r \cdot, 1$ & $r, 1$ & $v, v$ & "ln & 等 & 9,0 & $r \leqslant, 0$ & 19,7 & $r \cdot, 1$ & $17, \wedge$ & $\%$ & \\
\hline$\ldots 1$ & $r a, 1,1$ & $\wedge$ & & ir & $\Delta r$ & 04 & $0 \leqslant$ & iv & 7 & 70 & 14 & rv & $r \Lambda$ & $\varepsilon 9$ & rr & ت & \\
\hline 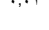 & 17, in & $n$ & (1) & $r, 1$ & $r \cdot, \varepsilon$ & $r \cdot, 0$ & 19,1 & $7, Y$ & 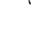 & 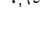 & $11, r$ & 11,9 & 19,7 & $r \varepsilon, r$ & 17,1 & $\%$ & 2 \\
\hline & rest & & & or & $\mathrm{AV}$ & 01 & 14 & 17 & & 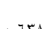 & it & $r \pi$ & \&1 & $r$. & rV & $ت$ & \\
\hline , & 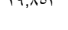 & : & ;,아 & 19,8 & $r 1,9$ & $1 \wedge\rangle$, & $r \varepsilon, Y$ & 0,9 & 1. & י & $\lambda, \varepsilon$ & $r r, 1$ & $r A, Y$ & $r$ & $1 \wedge, 9$ & $\%$ & $\circ$ \\
\hline & & & & or & A) & 04 & Ir & ri & & & 10 & $r$. & 17 & iv & 10 & ت & \\
\hline (., & 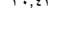 & 1 & 0,$0 ;$ & 19,8 & $r q, r$ & $r ., 0$ & $r, Y$ & $v, v$ & $=$ & 4 & $1 ., 0$ & $r,$. & $11, r$ & $\lfloor 9,9$ & 1,0 & $\%$ & 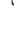 \\
\hline (1) & ry gor & & & $4 \pi$ & AV & $\varepsilon v$ & 7. & 14 & $y$ & 14 & $1 \varepsilon$ & $r$ & iv & vr & 9 & ت & $y$ \\
\hline 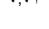 & (1) & " & 1) & $r r, r$ & $r 1,9$ & $i v, r$ & $r r, \cdot$ & 0,9 & 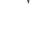 & 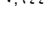 & $9, \wedge$ & $r, Y$ & 11,9 & $0 ., r$ & $7, r$ & $\%$ & 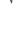 \\
\hline & & & & $\pi$ & $v_{\Lambda}$ & $\varepsilon r$ & $1 \leqslant$ & rr & & & 14 & $\mathrm{~m}$ & rA & ov & 1 & ت & \\
\hline 足 & $r, \ldots v$ & $0^{\circ}$ & $0,0+4$ & $r \varepsilon, r$ & $\uparrow \wedge, \uparrow$ & 10,1 & $r r, \varepsilon$ & $\Lambda, Y$ & $\pi$ & ז., & $11, r$ & ro,r & 19,9 & $r q, q$ & $\varepsilon, r$ & $\%$ & 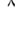 \\
\hline$\ldots$ & r1.799 & ir & $.0 . r$ & VT & 10 & ¿^ & $\leqslant r$ & ry & $r$ & 104 & ir & ro & rA & ra & rq & ت & , \\
\hline 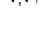 & 1,177 & . & 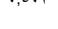 & $r \eta, \varepsilon$ & $r, 1$ & $1 v, 7$ & $10, \varepsilon$ & 9,0 & 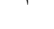 & 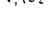 & $\lambda, \varepsilon$ & $T \leqslant, 0$ & 19,7 & $r v, r$ & $r \cdot, r$ & $\%$ & t \\
\hline (1) & $r=0$ & 7 & & 11 & Qr & $r q$ & 11 & rr & 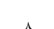 & $7 \leq r$ & it & ${ }^{\wedge} \wedge$ & m & «^ & $1 A$ & ت & 1 \\
\hline . & & & , & $r T, r$ & $r r, v$ & $1 r, r$ & $r T, r$ & $\Lambda, \varepsilon$ & & & 9,1 & 19,7 & ro,r & $r r, r$ & $r, T$ & $\%$ & \\
\hline (1) & rro & 今 & OOYY & II & av & \&1 & $\varepsilon r$ & ro & T & 704 & $1 \leqslant$ & $r \varepsilon$ & $T \varepsilon$ & rq & $r r$ & ت & 1) \\
\hline 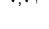 & 1,110 & ?" & 1, & $r r, r$ & $r 0,0$ & 10 & 17,9 & $9, Y$ & 1 & הוקו, & 9,1 & $r r, A$ & 17,1 & $r V, r$ & $r Y, \varepsilon$ & $\%$ & 11 \\
\hline & Y0.75 & 1 & & so & va & 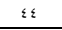 & $\mathrm{ru}$ & r. & & & ir & rr & rv & 71 & 11 & ت & ir \\
\hline , & $10, \pi 17$ & 1 & $0,0 \approx \lambda$ & 19,1 & $r \wedge, q$ & 19,1 & $r V, \lambda$ & $r, r$ & $p^{2}$ & 4 & $\lambda, \varepsilon$ & 10,8 & $r_{0, q}$ & $\varepsilon r, Y$ & $v, v$ & $\%$ & it \\
\hline
\end{tabular}

$$
\text { يتضح من الجدول السابق ما يلي: }
$$

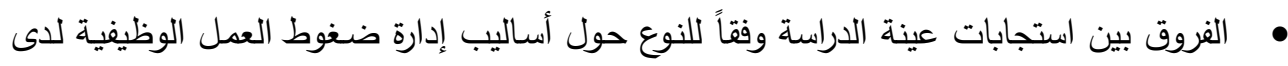
أعضاء هيئة التدريس ومعاونيهم: جاءت استجابات عينة الدراسة بأنها توجد فروق ذات دلانلة

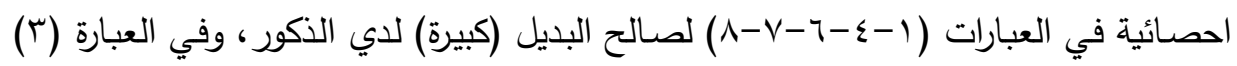

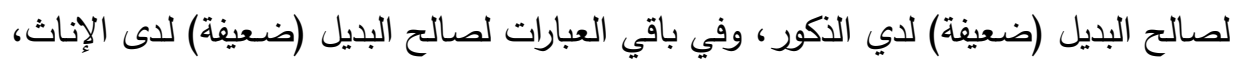

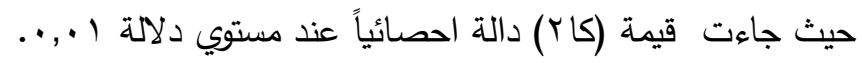

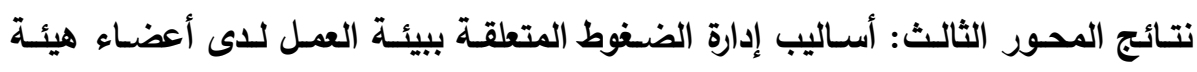


نظراً لوجود فروق ذات دلالة احصائية عينة الدراسة وفقاً للنوع والدرجة العلمية والكلية حول أسـاليب إدارة الضـغوط المتعلقة ببيئة العمل لدى أعضـاء هيئة التدريس ومعاونيهم، سيتم توضيح استجابات كلا منها على حده، كما هو موضح بالجدول التالي: جدول (ء)

استجابات عينة الدراسة وفقاً للنوع حول أساليب إدارة الضغوط المتعلقة ببيئة العمل لاى أعضاء

هيئة التدريس ومعاونيهم (ن = 17 ( )

\begin{tabular}{|c|c|c|c|c|c|c|c|c|c|c|c|c|c|c|c|c|c|}
\hline \multirow{3}{*}{ الدلالةت } & \multirow{3}{*}{ كابريـــة } & \multicolumn{7}{|c|}{ الإناث (rYr) } & \multicolumn{7}{|c|}{ الذكور (r \& 1$)$} & \multirow{3}{*}{\multicolumn{2}{|c|}{ العبارات }} \\
\hline & & & & & بائل & & & & \multirow[b]{2}{*}{ الترتيب } & \multirow[b]{2}{*}{ النسبي } & \multicolumn{5}{|c|}{ الثبائل } & & \\
\hline & & الترتيب & النوبي & ضعيفة جـأ & ضعيفة & متوسطة | - متوة & كبيرة & كبيرة & & & خداً & ضفيد & متوسطة & كبيرة & كبيرة & & \\
\hline \multirow{2}{*}{.,.$\cdot$} & \multirow{2}{*}{$r \leqslant, 0 \leqslant q$} & \multirow{2}{*}{$\varepsilon$} & \multirow{2}{*}{ r., } & $7 \lambda$ & $v_{0}$ & $\leqslant r$ & $v_{\text {v. }}$ & in & \multirow{2}{*}{ 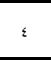 } & \multirow{2}{*}{$\cdot, 701$} & $\mathrm{r}$ & $r_{\lambda}$ & $1 A$ & TV & ir & ت & \multirow{2}{*}{, } \\
\hline & & & & $r \leqslant, 9$ & $r Y, 0$ & 10,4 & $r 0,1$ & 7,1 & & & $\xi, 9$ & $r 9,9$ & Ir,Y & $\lfloor 7,9$ & 9,1 & $\%$ & \\
\hline \multirow{2}{*}{,., 1} & \multirow{2}{*}{$r M, r \leqslant r$} & \multirow{2}{*}{ ir } & \multirow{2}{*}{, $\leqslant$ १६ } & vr & 91 & $\frac{\pi r}{r}$ & $\varepsilon v$ & $r$ & \multirow{2}{*}{ "1 } & \multirow{2}{*}{ r } & 10 & $r$. & $r \varepsilon$ & 0 o & 1. & ت & \multirow{2}{*}{ r } \\
\hline & & & & $r T, \varepsilon$ & $r r, r$ & 10,2 & $\mid V, r$ & $r, v$ & & & $1 ., 0$ & $r$ & $r r, \Lambda$ & $r \nu, \Lambda$ & $\mathrm{v}$ & $\%$ & \\
\hline \multirow{2}{*}{., 1} & \multirow{2}{*}{$r \varepsilon, \varepsilon v \varepsilon$} & \multirow{2}{*}{ 1. } & \multirow{2}{*}{., 01} & $7 \mathrm{n}$ & $\mathrm{rq}$ & $\leqslant 9$ & $\pi$ & 17 & - & . rer & 11 & $r r$ & $r r$ & 70 & ir & ت & r \\
\hline & & & & $r \varepsilon, q$ & $r \wedge, 9$ & $\mid v, q$ & $r r, r$ & 0,9 & 7 & , 709 & $\mathrm{v}, \mathrm{v}$ & $r \mathrm{rr}, \mathrm{s}$ & 10,8 & $\{0,0$ & 9,1 & $\%$ & \\
\hline 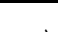 & 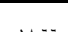 & 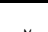 & 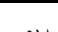 & o & Gr & or & $\Pi$ & ir & r & II) & $1 \leqslant$ & ro & rq & or & $\wedge$ & ت & 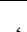 \\
\hline & $\lambda, M$ & 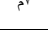 & A & $19, \lambda$ & $r \mu, Y$ & $19, \varepsilon$ & $r r, r$ & $\xi \varepsilon, \Lambda$ & & ; & $9, \Lambda$ & $r \varepsilon, 0$ & $r, r$ & $r q, 9$ & 0,1 & $\%$ & \\
\hline & & & & .99 & 99 & 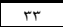 & $\xi v$ & ro & & & IV & $r A$ & 19 & $r r$ & 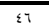 & ت & \\
\hline 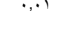 & $r r, r r v$ & 1 & ,0,4t & $r, \uparrow$ & $r \Pi, r$ & $\mid r, 1$ & $\mid v, r$ & Ir,A & 1 & $\cdot, 7 \wedge$ & 11,9 & 19,7 & $i r, r$ & $r r, 1$ & $r r, r$ & $\%$ & $0^{\circ}$ \\
\hline & 40 & 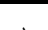 & ov. & $\frac{\pi r}{\varepsilon}$ & $M$ & $\xi \wedge$ & or & $\varepsilon r$ & $y$ & $-\gamma$ & ir & ro & 14 & 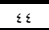 & ro & ت & . \\
\hline,,$\cdot 1$ & 17,090 & 1 & , OV & 10,2 & $\overline{r r, r}$ & $\mid Y, 4$ & $19, \varepsilon$ & $10, \varepsilon$ & $r$ & , TV₹ & 9,1 & $r \xi, 0$ & $11, r$ & $r \cdot, \Lambda$ & $r \varepsilon, 0$ & $\%$ & \\
\hline - & s & ir & $\Leftrightarrow x$ & A. & $9 r$ & $r$. & ov & $1 \varepsilon$ & 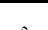 &. .07 & 11 & $r \varepsilon$ & $r 9$ & $\varepsilon r$ & $r v$ & ت & $x$ \\
\hline 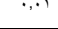 & $\{4,70 T$ & $\pi$ & , & $r q, r$ & $r r, v$ & 11 & $r+, 9$ & 0,1 & 0 &., 707 & $\begin{aligned}, v \\
\end{aligned}$ & $r r, \Lambda$ & $r, r, r$ & 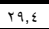 & 14,9 & $\%$ & \\
\hline & & & & 04 & $9 r$ & ro & $v^{\prime}$ & rq & & & IV & $r \varepsilon$ & $r A$ & 00 & 19 & ت & \\
\hline,., 1 & $r v, 10 \mathrm{~V}$ & $r$ & ., & $r ., 0$ & $r \varepsilon, 1$ & $9, \mathrm{r}$ & $r 0, r$ & $1 ., 7$ & ל & , & 11,9 & $17, \lambda$ & 19,4 & $r_{\lambda, 0}$ & $\mid r, r$ & $\%$ & A \\
\hline & 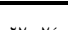 & 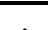 & & 71 & $\Delta V$ & $r 4$ & 10 & $r \varepsilon$ & . & $-\mu$ & Ir & $r 1$ & $r r$ & ov & 11 & ت & 0 \\
\hline$, \cdot, 1$ & $r y, \cdot Y \varepsilon$ & 0 & , or & $r Y, r$ & $r 1,9$ & $\mid r, r$ & $\overline{r r, A}$ & $\lambda, \Lambda$ & 9 & , & $\lambda, \varepsilon$ & $r, r, v$ & $T_{Y, \xi}$ & $r q, 9$ & 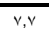 & $\%$ & 9 \\
\hline 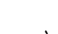 & $\ldots H$ & 年 & 5 s. & $n$ & $1 . \varepsilon$ & $r_{\Lambda}$ & $\therefore$ & 10 & r & $\rightarrow$ & r. & $r r$ & rr & OA & 1. & ت & 1 \\
\hline ו., & 18,11 & & 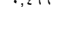 & $r r, r$ & $r \wedge, 1$ & $i r, q$ & $r,, 1$ & 0,0 & & 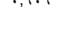 & $1 \xi, 0$ & $r r, 1$ & $10, \varepsilon$ & $\lfloor, \eta$ & $v_{,}$. & $\%$ & \\
\hline 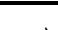 & \% & , & & $7 \lambda$ & $\Delta r$ & \&1 & $\pi$ & 11 & - & 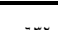 & 11 & ro & $r_{\Lambda A}$ & $O A$ & 11 & ت & , \\
\hline$, \cdot, 1$ & $r v, \cdot r$ & 9 & 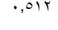 & $T \leqslant, 9$ & $r_{r, \ell}$ & $10,$. & $r r, 1$ & 7,4 & 1. & זTונ, & $y, y$ & $r \xi, 0$ & 19,9 & 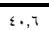 & $\overline{v, Y}$ & $\%$ & 11 \\
\hline & & & & ON & q. & $\llbracket \varepsilon$ & IV & $1 \varepsilon$ & & & 10 & ro & ro & 17 & ir & ت & \\
\hline & & & & $r, Y$ & $r r,$. & 17,1 & $r \xi, 0$ & 0,1 & & & 1,0 & $1 v, 0$ & $\mid v, 0$ & $\varepsilon \uparrow, Y$ & $\lambda, \varepsilon$ & $\%$ & \\
\hline & 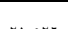 & $x$ & 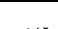 & 0. & $\overline{A V}$ & $\bar{n}$ & rᄉ & $r v$ & & & 10 & $r r$ & $\overline{r v}$ & $r \varepsilon$ & $\xi \xi$ & ت & \\
\hline$, \cdot, 1$ & $r, 0 Y\}$ & r & T, & $1 \Lambda, r$ & $r 1, q$ & $\overline{r r, r}$ & $1 r, 9$ & 15,7 & $r$ & גור, & 1,0 & $r r, 1$ & $1 \wedge, 9$ & $1, \lambda$ & $r \cdot, A$ & $\%$ & ir \\
\hline
\end{tabular}

يتضح من الجدول السابق ما يلي:

• الفروق بين استجابات عينة الدراسة وفقاً للنوع حول أساليب إدارة الضغوط المتعلقة ببيئة العمل يل

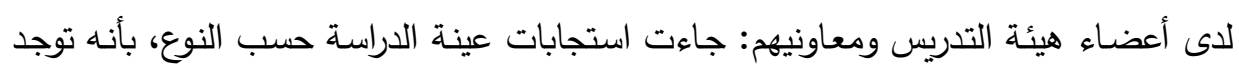

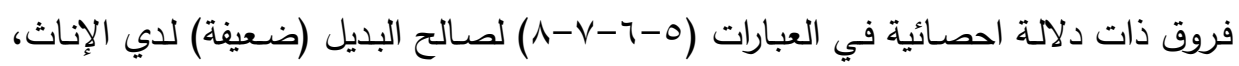

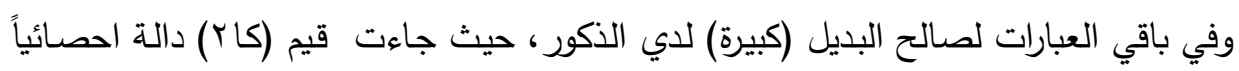
عند مستوي دلالة ا.,... نتائج المحور الرابع: أسـاليب إدارة ضغوط العمل الثخصية لدى أعضاء هيئة التدريس 
نظراً لوجود فروق ذات دلالة احصائية عينة الدراسة وفقاً للنوع والدرجة العلمية والكلية حول أسـاليب إدارة ضــوط العهـل الثخصـية لـدى أعضــاء هيئـة التـدريس ومعـاونيهم، سـيتم توضـيح استجابات كلا منها على حده، كما هو موضح بالجدول التالي: جدول (0)

استجابات عينة الاراسة وفقاً للنوع أساليب إدارة ضغوط العمل الثخصية لاى أعضاء هيئة التدريس ومعاونيهم (ن= 7 ( 1 )

\begin{tabular}{|c|c|c|c|c|c|c|c|c|c|c|c|c|c|c|c|c|c|}
\hline \multirow{3}{*}{ مستون } & \multirow{3}{*}{ قايمة } & \multicolumn{7}{|c|}{ الإناث (rVPr) } & \multicolumn{7}{|c|}{ 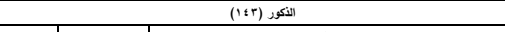 } & \multirow{3}{*}{\multicolumn{2}{|c|}{ العبارت }} \\
\hline & & \multirow[b]{2}{*}{ التزتيب } & \multirow{2}{*}{ النسبي } & \multicolumn{5}{|c|}{ الثايأل } & \multirow[b]{2}{*}{ النزتيب } & \multirow[b]{2}{*}{ التسبي } & \multicolumn{5}{|c|}{ البادل } & & \\
\hline & & & & ضطيفة & ضعيفة & متوسطة & كييرة & كبيرة جـأ & & & ضعيفة جأ & ضعيفة & متوسطة & كييرة & كييرة جنأ & & \\
\hline \multirow{2}{*}{$\ldots$} & \multirow{2}{*}{$i n, y y$} & \multirow{2}{*}{ tr } & \multirow{2}{*}{, } & «^ & 9 & $\leqslant 9$ & 7. & $r_{0}$ & \multirow{2}{*}{ ir } & \multirow{2}{*}{ r rint. } & 19 & $r \wedge$ & $m$ & $O A$ & ir & $ت$ & \multirow{2}{*}{, } \\
\hline & & & & $1 v, 7$ & $r r, r$ & $1 v, 9$ & $r r$ & $9, r$ & & & $1 r, r$ & 19,7 & $\mid \lambda, r$ & 5,1 & $\Lambda, \xi$ & $\%$ & \\
\hline \multirow{2}{*}{$\ldots$} & \multirow{2}{*}{$r \leqslant, Y_{Y}$} & \multirow{2}{*}{ v } & \multirow{2}{*}{., $07 \&$} & $\leqslant 9$ & $9 v$ & $\leqslant r$ & is & ri & \multirow{2}{*}{ v } & \multirow{2}{*}{ רor, } & 1. & $r$ & r) & $\because$ & r. & ن & \multirow{2}{*}{ r } \\
\hline & & & & $1 v, 9$ & $r_{0,0}$ & 10,4 & $r r, \varepsilon$ & $\begin{aligned}, y \\
\end{aligned}$ & & & $\mathrm{v},{ }^{\prime}$ & $r 1, r$ & $r 1, r$ & $r_{0, y}$ & 15 & $\%$ & \\
\hline \multirow{2}{*}{$\ldots$} & \multirow{2}{*}{$r \leqslant, r q$} & , & $.0 \leqslant\}$ & or & 47 & $s r$ & $6 r$ & \&. & , & (79. & $\lambda$ & $r$ & $r r$ & $r \xi$ & $\leqslant v$ & $\dot{0}$ & r \\
\hline & & & & 19 & $r_{0, r}$ & $\begin{array}{l}10,8 \\
\end{array}$ & 10,1 & $\begin{array}{l}1 \xi, y \\
\end{array}$ & & & 0,1 & 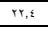 & $\begin{array}{rr}r, i \\
\end{array}$ & $17, \Lambda$ & $\begin{aligned} r r, 9 \\
\end{aligned}$ & $\%$ & \\
\hline 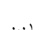 & $r i r$ & ir & דיר. & vr & $\Delta T$ & so & $r \xi$ & ra & A & 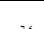 & 17 & 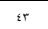 & "r & $r r$ & $\$$ & 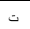 & 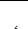 \\
\hline 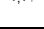 & , & & , & $r \bar{r}, \mathrm{~s}$ & 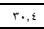 & 17,0 & $1 r, 0$ & $1 \varepsilon, r$ & & , net & $11, r$ & $r \cdot, r$ & 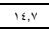 & 10,5 & $r A_{, Y}$ & $\%$ & \\
\hline & & & & or & $v_{A}$ & 81 & ov & $r_{0}$ & & & $i r$ & $r y$ & $r$ & or & $r$. & $\dot{5}$ & \\
\hline$\cdots$ & $r, 91$ & كُم & , orA & $r, q$ & $r_{\lambda, i}$ & 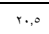 & $r ., q$ & $\overline{a, r}$ & $\wedge$ & 列, & 4,1 & $1 \times, 9$ & $r i, v$ & $\overline{r, \xi}$ & $1:$ & $\%$ & 。 \\
\hline 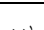 & $\mu_{r} \tau_{r}$ & U & or & $\leqslant \wedge$ & 1.1 & 0 s & $0 \leqslant$ & 19 & ] & 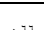 & 1. & $r \varepsilon$ & $m$ & $\$ 9$ & $r \xi$ & $ت$ & 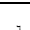 \\
\hline & 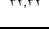 & & (2, & $2 v, 7$ & $r y$ & $19, \wedge$ & 19,1 & 0,9 & & 0,14 & $v_{, n}$, & $r r, \wedge$ & $\mid \lambda, r$ & $r \xi, r$ & 19,4 & $\%$ & \\
\hline$\ldots$ & $r\{, r\}$ & 1. & .045 & 01 & so & $\circ$ & $\pi$ & 10 & 1. & 列. & iv & r) & $r r$ & i^ & $r s$ & 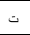 & v \\
\hline & & & & $r, 0$ & $m, 1$ & $19, \AA$ & $r r, 1$ & 0,0 & & & 11,9 & $r 1, Y$ & 17,1 & $r r, Y$ & 19,4 & $\%$ & \\
\hline & & & & $\therefore$ & $4 r$ & $\therefore$ & " & 19 & & & ir & $r Y$ & $r$ & $r y$ & 1. & ت & \\
\hline$\cdots$ & $\{., 1\}$ & $\wedge$ & , Ory & $\mu, r$ & $r_{\varepsilon, 1}$ & $\mu, r$ & $r r, r$ & v & 。 & זיוו, & ৭, & 10,8 & 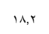 & $0 ., r$ & v & $\%$ & ^ \\
\hline , & rara & 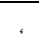 & $.00 \mathrm{c}$ & of & so & $\because$ & $\leadsto$ & ro & r & . & is & $r$. & "r & 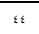 & 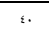 & 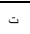 & 9 \\
\hline 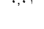 & 14,72 & $z$ & , & $19, \wedge$ & $m, 1$ & $1 \alpha, Y$ & $r r, r$ & $9, r$ & & & $1 r, 4$ & $1 \leqslant$, & $1 \xi, y$ & $r \cdot, \Lambda$ & $r_{\lambda}$ & $\%$ & \\
\hline$\ldots$ & ry, qq & 7 & .097 & so & MAA & iv & 0 \% & 19 & r & . & if & $m$ & 19 & os & 19 & 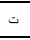 & i. \\
\hline & & & & 17,0 & $r r, r$ & $r \leqslant, 0$ & $19, \Lambda$ & v & 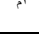 & & 9,1 & $r o, r$ & $1 r, r$ & $r y, A$ & $\mid r, r$ & $\%$ & \\
\hline$\therefore$ & ra & $r$ & .0.04r & $\$ 9$ & $A V$ & $\pi$ & «^ & 79 & : & . & ir & $r v$ & 79 & $r_{A}$ & $r y$ & ن & ." \\
\hline 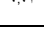 & 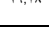 & 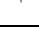 & , & $\begin{array}{ll}v, 9 \\
\end{array}$ & $\begin{aligned} 1,9 \\
\end{aligned}$ & $r r$ & $\begin{array}{ll}v, r \\
\end{array}$ & $1 \cdot, 1$ & 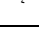 & & $\lambda$ & $\begin{array}{ll}1 \wedge, 9 \\
1\end{array}$ & 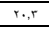 & $\begin{aligned} 1, r \\
\end{aligned}$ & $\begin{aligned} \\
\end{aligned}$ & $\%$ & \\
\hline & $\because \pi$ & 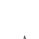 & 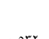 & 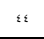 & $1 . \lambda$ & $\lll$ & . & rv & & & ir & $m$ & is & $0 \%$ & $r$ & ت & \\
\hline , & $\pi,+\lambda$ & $e^{\lambda}$ & , क्या & 17,1 & $r q, r$ & 17,1 & $a, r$ & 9,9 & ${ }^{4}$ &, 110 & १, & ro,r & $r, q$ & $r y, A$ & 10,8 & $\%$ & ir \\
\hline
\end{tabular}

$$
\text { يتضح من الجدول السابق ما يلي: }
$$

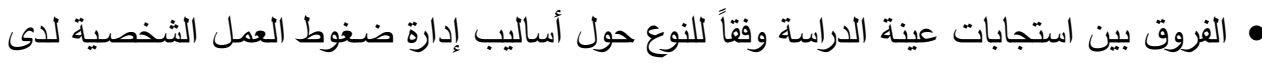

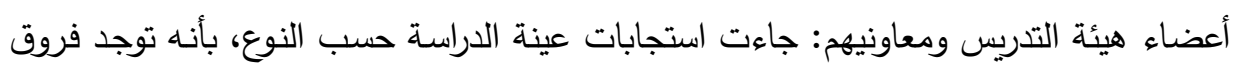

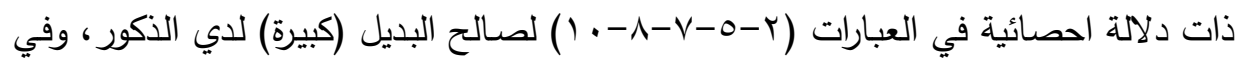

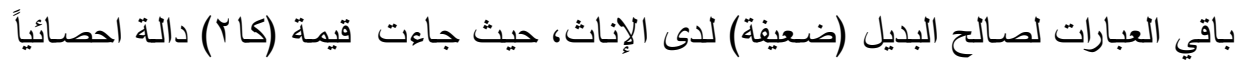
عند مستوي دلالة ا.,.•. التوصيات:

في ضوء ما أسفر عنه الإطار النظري للبحث الحالي، وبناءً على ما توصلت إليه الدراسة

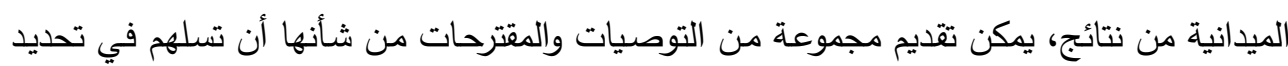


الأسـاليب المناسبة، التي يمكن أن يستخدمها أعضـاء هيئة التدريس ومعـاونيهم في إدارة ضـغوط

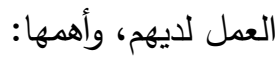

1 - توضيح المسئوليات بشكل إجرائي في كافة الأقسام العلمية بكليات التربية.

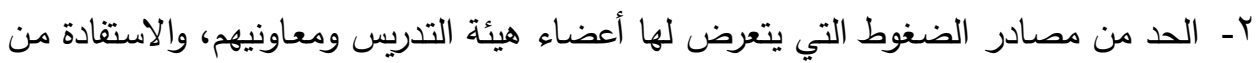
إيجابياتها. r- إعداد كوادر مؤهلَة من أعضاء هيئة التدريس ومعاونيهم؛ ذوو خبرة وكفاءة في تفعيل الأسلوب إنهاب الأنسب لمواجهة الضغوط وترقية البحث العلمي. ع- زيادة المنح والمكافآت المقدمة لأعضاء هيئة التدريس ومعاونيهم.

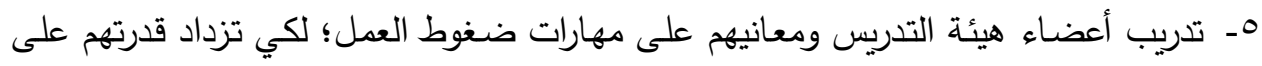
التكيف مع الضغوط التي يواجهونها في بيئة عملهم.

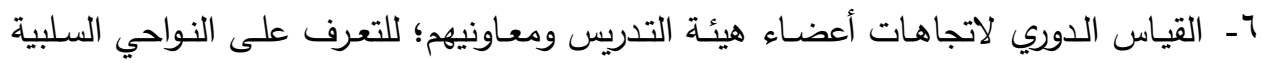

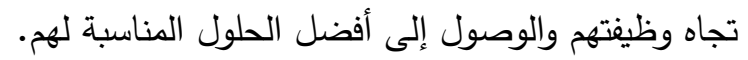

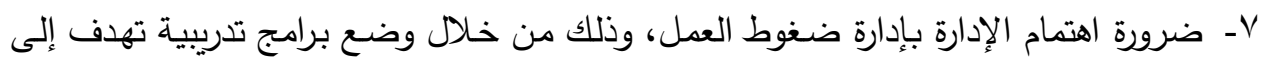

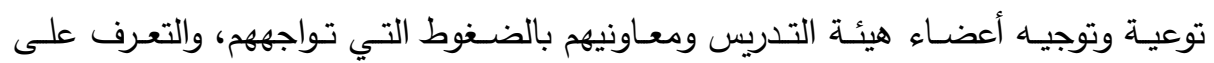
أسبابها وكيفية التعامل معها.

1- المساندة الاجتماعية لأعضاء هيئة التدريس ومعاونيهم، وزيادة الرعاية الصحية والنفسية.

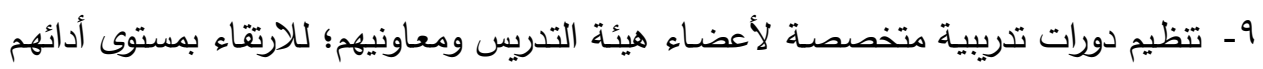

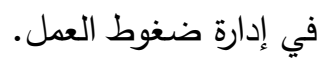
• ا-توفير ثقافة تتظيمية داخل كليات التربية؛ لتوعيـة أعضـاء هيئة التدريس ومعاونيهج بأهمية

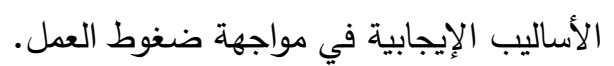
المر اجع المستخدمة في البحث: الإيثة

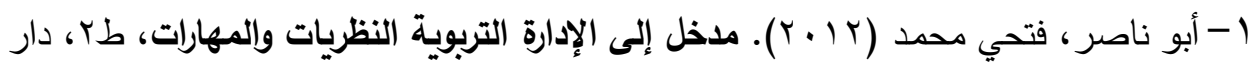
المسيرة، عمان. Y - اسماعيل، بشرى (؟ . . ץ). ضغوط الحياة والاضطرابات النفسية، مكتبة الأنجلو المصرية، القاهرة. 
ب- اسماعيل، على عبد ربه حسين (ع ا • ب). أساليب مديري الددارس الثانوية العامة في إدارة

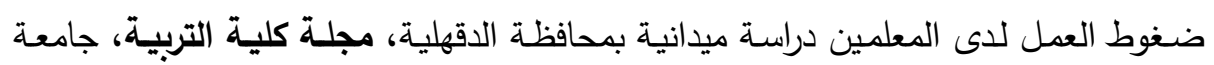

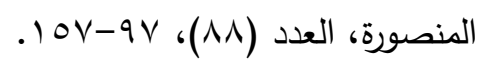

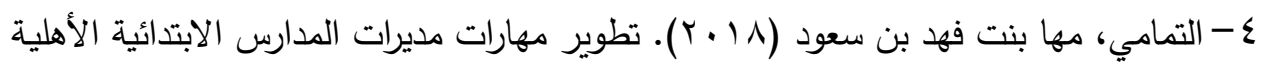

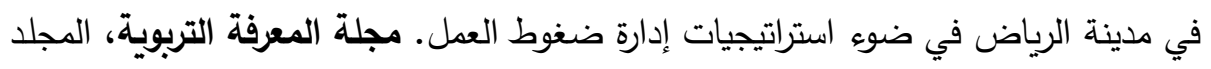

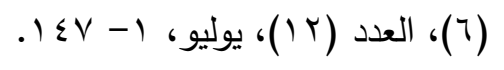

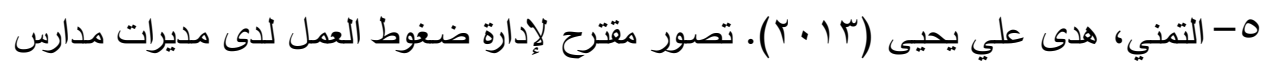

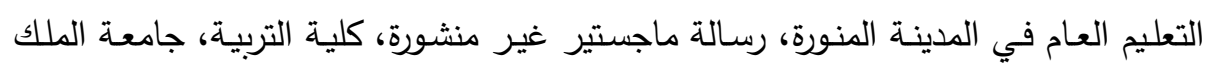

خالد، المملكة العربية السعودية.

T- الجرادات، محمود خالد (• ( • ( ): أساليب التكيف مع ضغوط العمل في كلية المعلمين بحائل

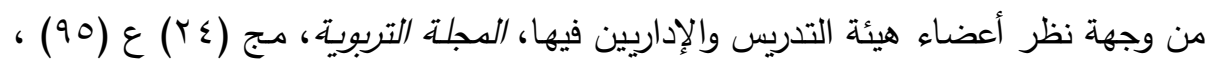

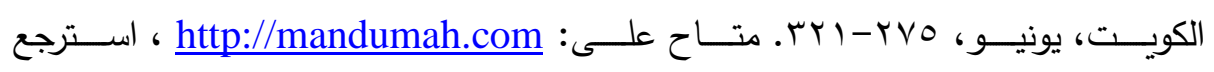

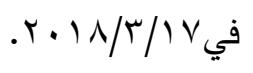

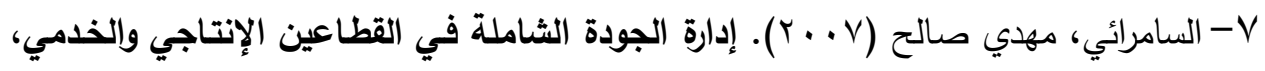
دار جرير للنشر والتوزيع، عمان.

^- الصيرفي، محمد (1 . . ץ). الضغط والقلق الإداري، مؤسسة حورس الدولية، الاسكندرية.

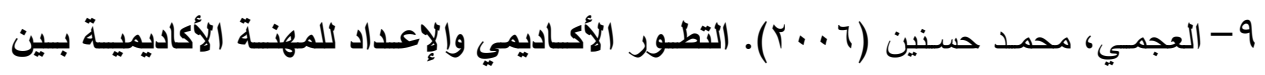
تحديات العولمة ومتطلبات التدويل، العالمية للنشر والتوزيع، الجيزة.

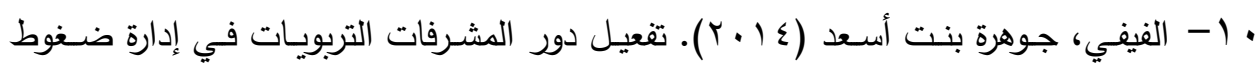

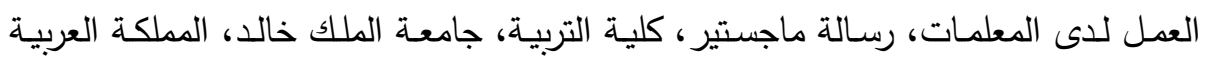
السعودية.

I ا - حسـان، حسن محمد؛ العجمي، محمد حسنين (V ... r). الإدارة التربويـة، دار المسيرة، عمان.

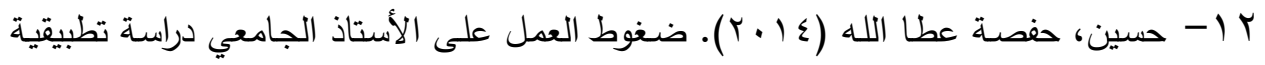

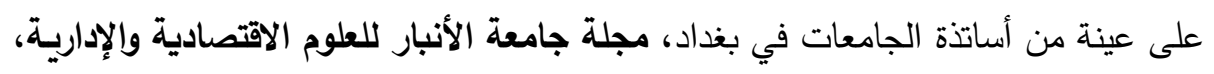

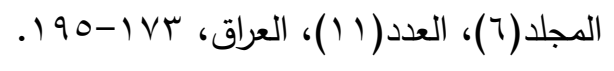




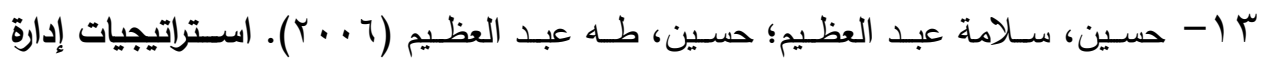
الضغوط التربوية والنفسية، دار الفكر ، عمان.

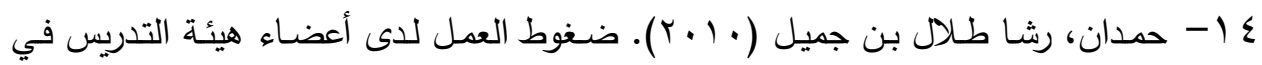

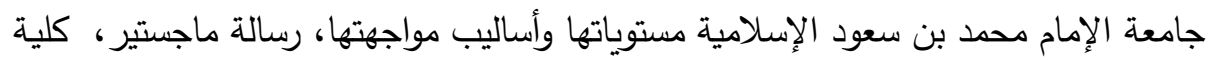
العلوم الاجتماعية، جامعة الإمام محمد بن سعود الإسلامية.

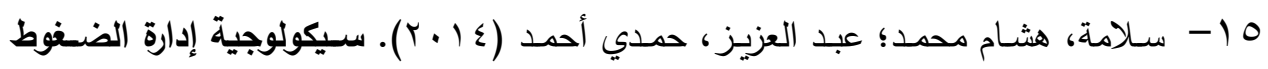
الفنيات- البرامج- التطبيقات، دار الفكر العربي، القاهرة.

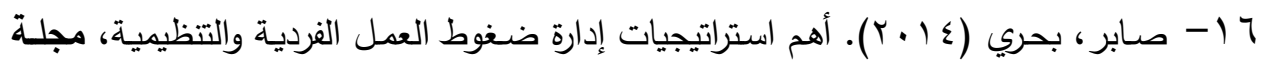

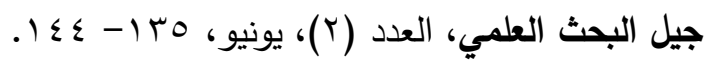
IV

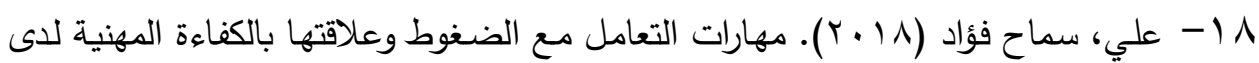

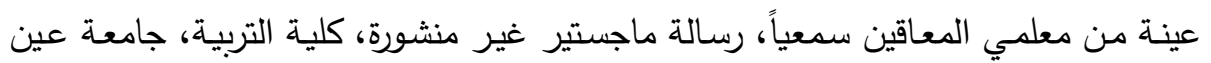

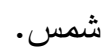

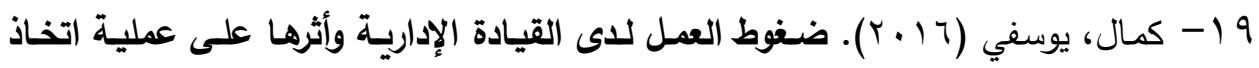
القرار، مكتبة الوفاء القانونية، الإسكندرية.

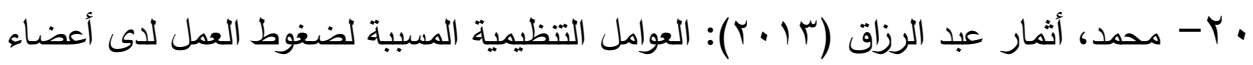

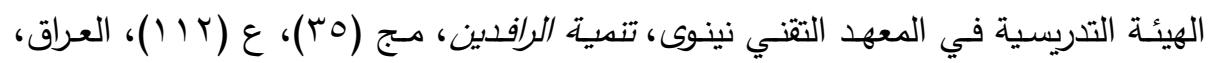

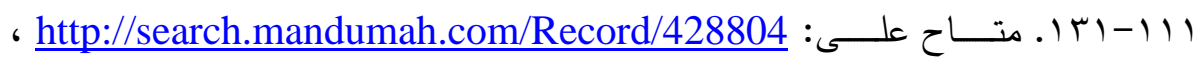

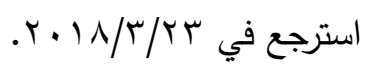

ا Y- ميخائيل، إنجى طلعت نصـيف (• ( • ( ). تصـور مقترح لإدارة ضـغوط العمل لتحسين الأداء الوظيفي لأعضاء هيئة التدريس دراسة ميدانية على جامعة الزقازيق. رسالة ماجستير غير منشورة. كلية التربية جامعة الزقازيق.

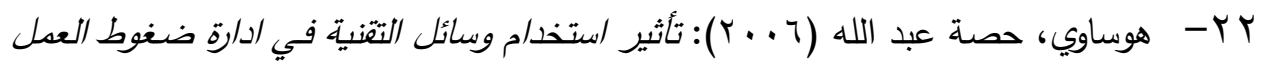
للى عضوات هيئة التدريس في كليات البنات بككة المكرمة من وجهة نظرهن، رسالة دكتوراه

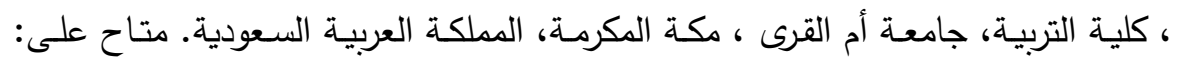
(mttps://WwW.manaraa.com 


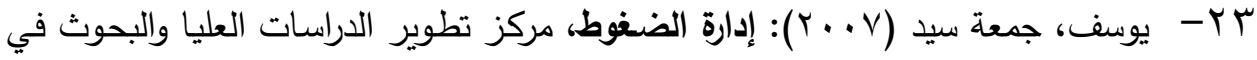

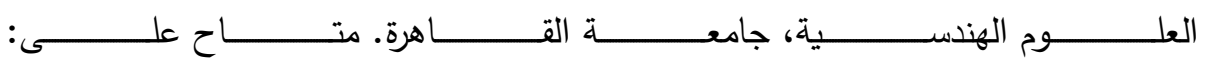

http://www.pathways.cu.edu.eg/subpages/training_courses/Stress

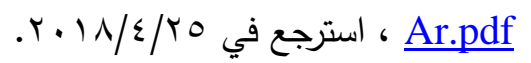

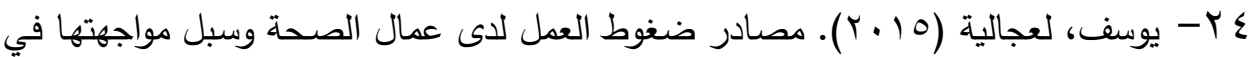

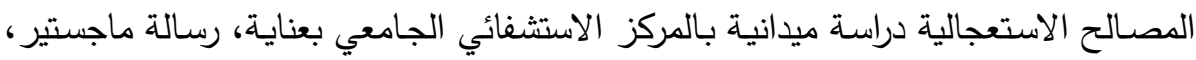

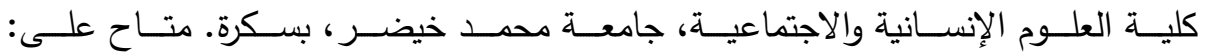

1http://thesis.univ-biskra.dz/1280/1/Psy_m3_2015.pdf

$$
. r \cdot 11 / 11 / 11
$$

25- Burke, Michelle (2013): Managing Work-Related Stress in the District Nursing Workplace, British Journal of Community Nursing, Vol. 18, No. 11, 535-538. Available at: https://www.magonlinelibrary.com/doi/10.12968/bjen.2013.18.11.535 Retrieved in 29/11/2018.

26- Michailidis, Maria; Asimenos, Andreas (2002): Occupational stress as it relates to higher education, individuals and organizations, 19, 137-147. Available at: https://content.iospress.com/articles/work/wor00250, Retrieved in $1 / 4 / 2018$.

27- Moeller, Christin; Chung-Yan, Greg A. (2013): Effects of Social Support on Professors' Work Stress, International Journal of Educational Management, 27 (3), 188-202. Available at: https://eric.ed.gov/?redir=http\%3a\%2f\%2fdx.doi.org\%2f10.1108\%2f0 9513541311306431 . Retrieved in 23/3/2018.

28- Park, Jungwee (2007): Work Stress and Job Performance, Perspectives, December, 5-17. Available at: https://www.statcan.gc.ca/pub/75-001-x/2007112/article/10466eng.pdf . Retrieved in 20/3/2018.

29- Straub, R. O. (2012): Health psychology: A bio psychosocial approach, $\left(3^{\text {rd }}\right.$ ed.). New York: Worth Publishers. Available at: https://www.amazon.com/Health-Psychology-BiopsychosocialApproach-Richard/dp/B007S3VUBA 